BNWL-2240

NRC-1 \& 3

\title{
Comparative Analysis of Pellet-Cladding Interaction from IFA-431 and IFA-432 Halden Reactor Tests
}

by

C. R. Hann

R. K. Marshall

July 1977

Prepared for:

Fuel Behavior Research Branch

Division of Reactor Safety Research

United States Nuclear Regulatory Commission 
NOTICE

This report was prepared as an account of work sponsored by the Lnited States Gcvernment. Neither the United States nor the United States Nuclear Regulatory Commission, nor any of their employees, nor any of their contractors, subcontractors, or their employees, makes any warraniy, exprass or implied, or assumes any legal liability or responsibility for the accuracy, completeness or usetulness of any information, apparatus, product or process disclosed, or represents that its use would not infringe privately owned rights.

\author{
PACIFIC NORTHWEST LABORATORY \\ operated by \\ BATTELLE \\ for the \\ ENERCY RESEARCH AYD DEVELOPMENT ADMINISTRATION \\ Under Contract EY-76-C-05-7830
}

\begin{tabular}{|c|c|}
\hline \multicolumn{2}{|c|}{$\begin{array}{c}\text { Pitinted in the United States of Ammrica } \\
\text { Available from } \\
\text { Vationai Technical Intormation Service } \\
\text { U.S. Department of Commerce } \\
5285 \text { Port Royal Road } \\
\text { Springrietc, Virg nia } 22151\end{array}$} \\
\hline Price: Printed Cop & - : Microficre $\$ 3.00$ \\
\hline - Pages & $\begin{array}{c}\text { NTIS } \\
\text { Selling Frice }\end{array}$ \\
\hline $001-025$ & 54.50 \\
\hline $026-050$ & $\$ 5.00$ \\
\hline $051-075$ & $\$ 5.50$ \\
\hline $076-100$ & $\$ 6.00$ \\
\hline $101-125$ & 55.50 \\
\hline $126-150$ & 57.00 \\
\hline $157-175$ & 57.7 \\
\hline $176-200$ & 58.50 \\
\hline $201-225$ & 58.75 \\
\hline $22 E-250$ & $\$ 9 \infty 0$ \\
\hline $25 i-275$ & 510.00 \\
\hline $275-300$ & 590.25 \\
\hline
\end{tabular}


COMPARATIVE ANALYSIS OF PELLET-CLADDING INTERACTION FROM IFA-431 AND IFA-432

HALDEN REACTOR TESTS

by

C.R. Hann

R.K. Marshal1

Ju1y, 1977

Prepared for:

Fuel Behavior Research Branch

Division of Reactor Safety Research

United States Nuclear Regulatory Commission

\section{BATTELLE}

Pacific Northwest Laboratories

Richland, Washington 99352 


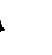

\author{
,
}




\section{ACKNOWLEDGMENITS}

The authors wish to acknowledge the support of Dr. W. V. Johnston and H. H. Scott of the Fuel Behavior Research Branch. The assistance of J. A. Christensen and the Halden Project staff during the design and irradiation is appreciated as are the comments of D. D. Lanning and R. E. Williford during the data reduction and evaluation period. 


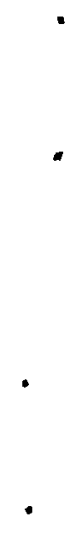




\section{CONTENTS}

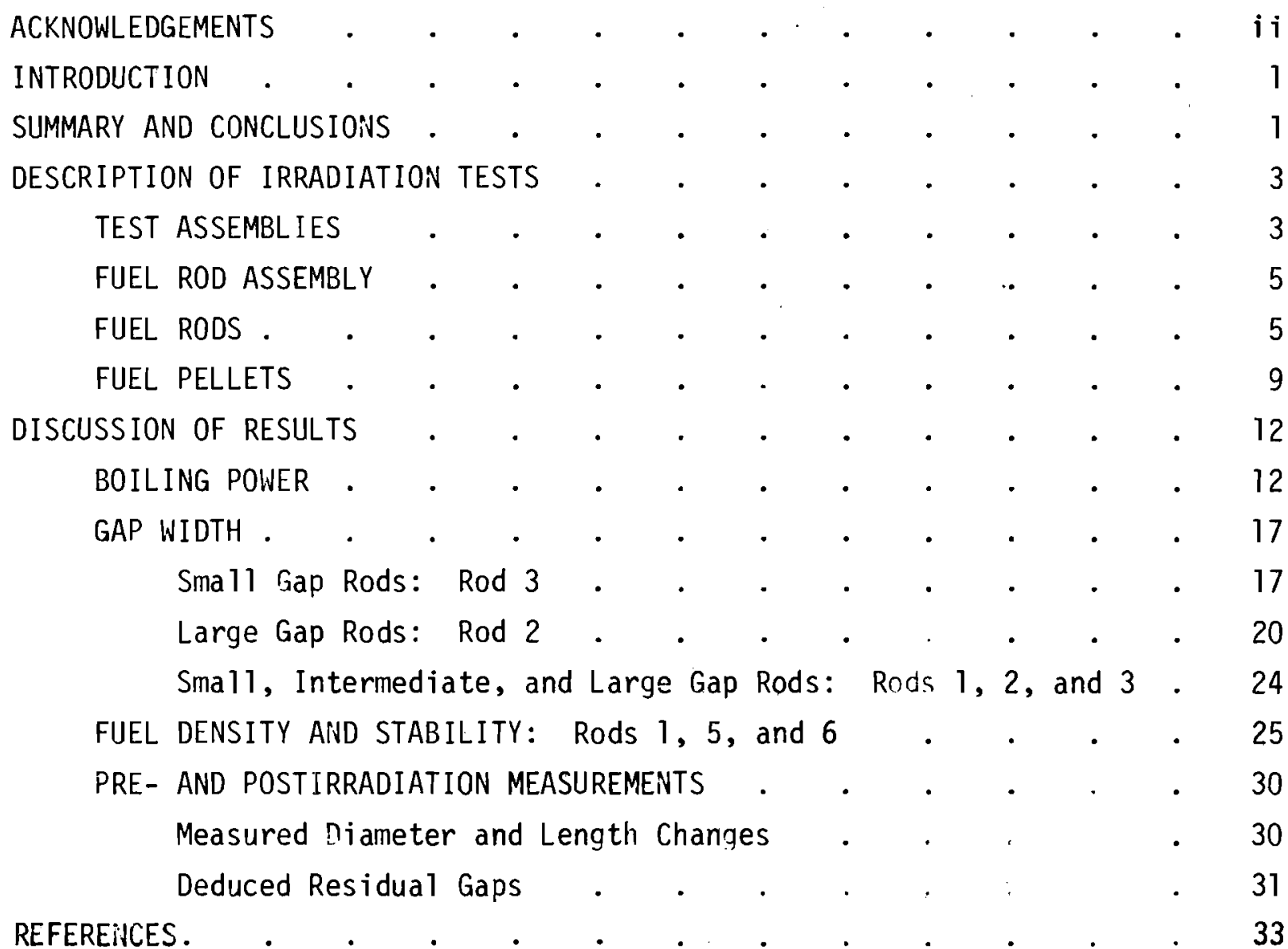





\section{$\underline{\text { LIST OF FIGURES }}$}

1. Schematic of Instrumented Fuel Assembly--IFA-431 . . . . . . 6

2. Arrangement of Temperature Sensors, Neutron Detectors, and

Fuel Relative to Reference Axial Thermal Flux Profile, IFA-431 and IFA-432

3. Location of Test Assemblies in the Reactor and Fuel Rod

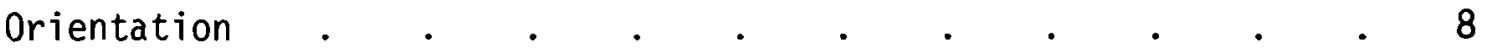

4. Schematic of Instrumented and Noninstrumented Fuel Rods

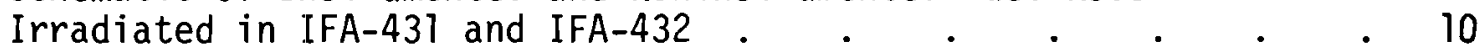

5. A Comparison of Elongation Detector Outputs During Ramp Al and Bl for Rod 1 in IFA-431 . . . . . . . 13

6. Schematic Arrangement of Fuel Rod Elongation Measurement

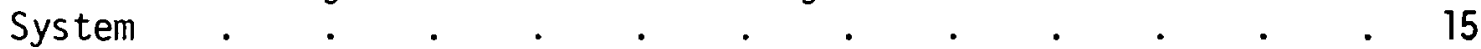

7. Elongation Detector Output as a Function of Boiling Power at Constant Fuel Rod Linear Heat Rating for IFA-431 • • . . . 16

8. Ramps for Rods 1, 2, 5, and 6 During Calibration Run, Ramp B1-IFA-431

9. Ramp for Rod 3 During Calibration Run, Ramp Bl-IFA-431 . . . 18

10. Fuel Rod Elongations for Rod 3, IFA-431 . . . . . . . . . 19

11. Fuel Rod Elongations for Rod 3, IFA-432 . • • • • • . . . 19

12. Fuel Rod Elongations for Rod 2, IFA-431 . . . . . . . . . 21

13. Fuel Rod Elongations for Rod 2, IFA-432 . . . . . . . 22

14. Fuel Stack with Displaced Pellet Fragment . . . . . . . 23

15. Fuel Rod Elongations for Rod 1, IFA-431 . . . . . . . . . 24

16. Fuel Rod Elongations for Rod 1, IFA-432 . . . . . . . . 25

17. Fuel Rod Elongations for Rod 5, IFA-431 . . . . . . . . . 27

18. Fuel Rod Elongations for Rod 5, IFA-432 . . . . . . . . 27

19. Fuel Rod Elongations for Rod 6, IFA-431 • . . . . . . . . 28

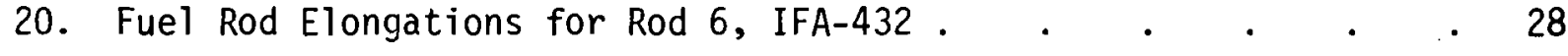


. . 


\section{LIST OF TABLES}

1 HBWR Operating Data . . $\quad$. $\quad$. $\quad$. $\quad$. $\quad$. $\quad . \quad$. 3

2 Design Parameters and Instrumentations for IFA-431 and IFA-432 - 4

3 Comparison of Cladding Elongation for Ramp Gl-IFA-431 • . $\quad 29$

4 Pre- and Postirradiation Measurements for Helium Filled

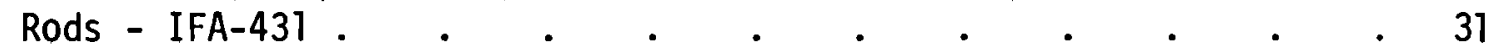

5 Results of Deduced Gap Widths for Helium Filled Rods IFA-431 • • • • • • • • • • • • 32 


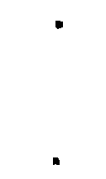




\author{
COMPARATIVE ANALYSIS OF PELLET-CLADDING INTERACTION FROM IFA-431 AND \\ IFA-432 HALDEN REACTOR TESTS \\ C. R. Hann and R. K. Marsha 11
}

\begin{abstract}
INTRODUCTION
The Battelle Pacific Northwest Laboratories are conducting irradiation tests in the Halden Boiling Water Reactor (HBWR) under the sponsorship of the Fuel Behavior Research Branch of the Nuclear Regulatory Commission. The objectives of the program are to 1) provide we11-characterized data for verifying computer codes used for reactor safety analysis and 2) develop improved analytical models for portions of these codes.

To assist in accomplishing these objectives, two test assemblies containing a total of 12 instrumented fuel rods were irradiated in the HBWR to obtain we11characterized data for fuel operating in the linear heat ranges of commercial nuclear power plants. These data are needed for verification of GAPCONTHERMAL ${ }^{(1)}$ and FRAP ${ }^{(2)}$ computer codes and will provide a series of benchmarks for indexing other thermal performance codes used for reactor safety analysis.
\end{abstract}

\title{
SUMMARY AND CONCLUSIONS
}

Two essentially identical test assemblies, IFA-431 and IFA-432, each containing six instrumented fuel rods, were irradiated under similar conditions in the HBWR. Parameters in the test include pellet-cladding gap size and/or gap eccentricity, fill gas composition, fuel density and stability, linear heat rating, and burnup. The BWR- 6 geometry except for length, a $95 \%$ theoretical density (TD) pellet, a $0.229 \mathrm{~mm}$ ( $9 \mathrm{mils}$ ) diameter gap, and helium fill gas were selected for the reference rod.

Each assembly consisted of one sma11 gap rod, $0.051 \mathrm{~mm}$ (2 mi1s) or $0.076 \mathrm{~mm}$ ( $3 \mathrm{mils}$ ), to act as an internal power standard, one large gap rod, $0.381 \mathrm{~mm}$ (15 mi1s), to simulate instantaneous densification, and four intermediate gap rods, $0.229 \mathrm{~mm}(9 \mathrm{mils})$. A11 of the rods were filled with helium at one atmosphere pressure except for one of the intermediate gap rods which was 
filled with xenon at atmospheric pressure. The tehavior of the xenon filled roas is discussed in Reference 3 . A11 rods contained $\mathrm{UO}_{2}$ flat endea pellets enriched to $10 \mathrm{w} / 0^{235} \mathrm{U}$.

Each fuel rod was instrumented with one cladding elongation sensor to detect the time and extent of pellet-cladding interaction (PCI) and with two temperature sensors to measure the central fuel temperature near the upper and lower end of each rod. Three rods in each asseribly were eacli equipped with a pressure transducer to monitor the plenum pressure.

IFA-431 was designed to operate at $330 \mathrm{~W} / \mathrm{cm}(10 \mathrm{KW} / \mathrm{ft})$ and was successfully irradiated to a goal buncile average burnup of $370 \mathrm{GJ} / \mathrm{kgM}$ (4300 MWd/MTM). IFA-432 was designed to operate at $490 \mathrm{~W} / \mathrm{cm}(15 \mathrm{KW} / \mathrm{ft})$ and is still under irradiation to a maximum goal burnup of $1730 \mathrm{GJ} / \mathrm{kgM}(20,000 \mathrm{MWd} / \mathrm{MTM})$. The assemblies were irradiated in different channels starting at different times. Both assemblies experienced a refueling shutdown of approximately four months duration after a burnup of approximately $215 \mathrm{GJ} / \mathrm{kglf}$ (2500 M!dd/iT/M) without removal from the reactor.

The conclusions derived from these tests are as follows:

- The unstable fuel caused less cladding elongation than the reference (stable) fuel in IFA-431 and greater elongations in IFÁ-432. This difference is attributed to densification in IFA-431 and to higher linear heat ratings and/or ramp rates in IFA-432.

- Fuel having a significantly lower thermal conductivity than the reference fuel caused greater cladding elongations than the reference fuel.

- At a burnup of approximately $260 \mathrm{GJ} / \mathrm{kgM}$ (3000 MWd/MTM), PCI occurred in al1 rods regardless of initial gap size or fuel type at approximately the same average 1 inear heat rating, 260-290 W/cm $(7.9-8.8 \mathrm{~kW} / \mathrm{ft})$. The elongations resulting from the PCI were affected by gap size and fuel type.

- The mode of PCI appeared to be affected by gap size. In sma11 and intermediate size gap rods, PCI appeared to occur as a result of gross movement of pellet fragments to the cladding, whereas in the large gap rods PCI appeared to occur as a result of localized movement of fragments into the gap. 


\section{DESCRIPTION OF IRRADIATION TESTS}

Two test assemblies were irradiated in different channels in the Halden Boiling Water Reactor (HBWR) located in Norway. The reactor is a natural circulation reactor which currently operates at a power level of $12 \mathrm{MW}$. The reactor operating data are shown in Table 1.

\section{TABLE 1. HBWR Operating Data}

$\begin{array}{ll}\text { Power Level } & 12 \mathrm{MW} \\ \text { Reactor Pressure } & 34 \mathrm{~atm}(500 \mathrm{psi}) \\ \text { Heavy Water Saturation Temperature } & 240^{\circ} \mathrm{C}\left(464^{\circ} \mathrm{F}\right) \\ \text { Plenum Inlet Temperature } & 237^{\circ} \mathrm{C}\left(459^{\circ} \mathrm{F}\right) \\ \text { Thermal Flux } & \sim 3 \times 10^{13} \mathrm{n} / \mathrm{cm}^{2}-\mathrm{sec} \\ \text { Fast Flux }(>1 \mathrm{MeV}) & \sim 5 \times 10^{11} \mathrm{n} / \mathrm{cm}^{2}-\mathrm{sec} / \mathrm{W} / \mathrm{g} \\ \text { Average Fuel Power Density } & 14.8 \mathrm{~W} / \mathrm{g}\end{array}$

\section{$\underline{\text { TEST ASSEMBLIIES }}$}

The two assemblies, each containing a cluster of six instrumented fuel rods, are essentially identical in design with one (IFA-431) operating at a linear heat rating (LHR) of $330 \mathrm{~W} / \mathrm{cm}(10 \mathrm{~kW} / \mathrm{ft}$ ) and the other (IFA-432) operating at $490 \mathrm{~W} / \mathrm{cm}(15 \mathrm{~kW} / \mathrm{ft})$. IFA-431 beqan operation in June of 1975 and was discharged after reaching an average goal burnup of $370 \mathrm{GJ} / \mathrm{kgM}$ (4300 MWd/MTM) in February of 1976. IFA-432 was charged into the reactor in December 1975 and will run until late in 1977. After reaching a burnup of approximately $215 \mathrm{GJ} / \mathrm{kgM}$ (2500 MWd/MTM), both assemblies experianced a shutdown of approximately four months duration for reactor refueling and maintenance. During this time, neither assembly was removed from the reactor. The design parameters and instrumentation for the test assemblies are shown in Table 2.

Test assembly instrumentation includes six vanadium neutron detectors to monitor the neutron flux adjacent to the fuel rods and one cobalt neutron detector to monitor the neutron flux changes during power transients. 
TABLE 2. Design Parameters and Instrumentation for IFA-437 and IFA-432

\begin{tabular}{|c|c|c|c|c|c|c|c|c|c|c|c|c|c|}
\hline \multirow{3}{*}{$\begin{array}{l}\text { Rod } \\
\text { ivo. }\end{array}$} & \multirow{2}{*}{\multicolumn{2}{|c|}{ Pellet ${ }^{(a)}$ oD }} & \multirow{2}{*}{\multicolumn{2}{|c|}{$\begin{array}{c}\text { Cold } \\
\text { Diametral Gap }\end{array}$}} & \multirow{3}{*}{$\begin{array}{r}\text { Fill } \\
\text { Gas } \\
\end{array}$} & \multirow{3}{*}{$\begin{array}{l}\text { Fuel } \\
\text { Density } \\
\% \text { TD }\end{array}$} & \multirow{3}{*}{$\begin{array}{l}\text { Fuel } \\
\text { Type }\end{array}$} & \multirow{3}{*}{$\begin{array}{l}\text { Burnup } \\
\text { GJ/kgM }\end{array}$} & \multirow{3}{*}{$\begin{array}{l}\text { Burnup } \\
\text { MWd/MTM }\end{array}$} & \multicolumn{4}{|c|}{ Instrumentation } \\
\hline & & & & & & & & & & \multicolumn{2}{|c|}{ Temperature } & \multirow{3}{*}{$\frac{\text { Pressure }}{\mathrm{PT}(\mathrm{C})}$} & \multirow{3}{*}{$\begin{array}{l}\text { Cladding } \\
\text { Length } \\
\text { ES }(d)\end{array}$} \\
\hline & $\mathrm{mm}$ & in. & $\mathrm{mm}$ & mils & & & & & & Upper & Lower & & \\
\hline 1 & 10.681 & 0.4205 & 0.229 & 9 & $\mathrm{He}$ & 95 & Stable & 345 & $(4,000)$ & $\mathrm{TC}^{(\mathrm{b})}$ & TC & & \\
\hline 2 & 10.528 & 0.4145 & 0.381 & 15 & He & 95 & Stable & 345 & $(4,000)$ & TC & TC & - & ES \\
\hline 3 & 10.858 & 0.4275 & 0.051 & 2 & He & 95 & Stable & 345 & $(4,000)$ & TC & TC & -- & ES \\
\hline 4 & 10.681 & 0.4205 & 0.229 & 9 & $\mathrm{Xe}$ & 95 & Stable & 345 & $(4,000)$ & TC & TC & -- & ES \\
\hline 5 & 10.681 & 0.4205 & 0.229 & 9 & $\mathrm{He}$ & 92 & Stable & 345 & $(4,000)$ & TC & TC & PT & ES \\
\hline 6 & 10.681 & 0.4205 & 0.229 & 9 & $\mathrm{He}$ & 92 & Unstable & 345 & $(4,000)$ & TC & TC & PT & ES \\
\hline \multicolumn{14}{|c|}{ IFA-432 - Peak Power - $490 \mathrm{~W} / \mathrm{cm})(15 \mathrm{~kW} / \mathrm{ft})$} \\
\hline 1 & 10.681 & 0.4205 & 0.229 & 9 & He & 95 & Stable & 1730 & $(20,000)$ & TC & $T C$ & PT & ES \\
\hline 2 & 10.528 & 0.4145 & 0.381 & 15 & $\mathrm{He}$ & 95 & Stable & 345 & $(4,000)^{(e)}$ & $U T^{(f)}$ & TC & -- & ES \\
\hline 3 & 10.858 & 0.4265 & 0.076 & 3 & He & 95 & Stable & 345 & $(4,000)^{(e)}$ & TC & TC & -- & ES \\
\hline 4 & 10.681 & 0.4205 & 0.229 & 9 & $\mathrm{Xe}$ & 95 & Stable & 345 & $(4,000)^{(e)}$ & TC & TC & -- & ES \\
\hline 5 & 10.681 & 0.4205 & 0.229 & 9 & $\mathrm{He}$ & 92 & Stable & 1730 & $(20,000)$ & TC & TC & PT & ES \\
\hline 6 & 10.681 & 0.4205 & 0.229 & 9 & $\mathrm{He}$ & 92 & Unstable & 1730 & $(20,000)$ & TC & TC & PT & ES \\
\hline 7 & 10.528 & 0.4145 & 0.381 & 15 & $\mathrm{He}$ & 95 & Stable & 1380 & $(16,000)$ & -- & -- & -- & -- \\
\hline 8 & 10.681 & 0.4205 & 0.229 & 9 & $\mathrm{He}$ & 95 & Stable & 1380 & $(16,000)$ & -- & -- & -- & -- \\
\hline 9 & 10.732 & 0.4225 & 0.179 & 7 & $\mathrm{He}$ & 95 & Stable & 1380 & $(16,000)$ & -- & -- & -- & -- \\
\hline
\end{tabular}

(a) All pellets have flat ends and are $12.7 \mathrm{~mm}(0.5 \mathrm{in.})$ long. The cladding for all rods has an OD of $12.789 \mathrm{~mm}(0.5035 \mathrm{in}$ 。) and an ID of $10.909 \mathrm{~mm}(0.4295)$ 。

(b) $\mathrm{TC}=$ Thermocouple

(c) $P T=$ Pressure Transducer

(d) $E S=$ Elongation Sensor

(e) Removable rods can be replaced by rods 7,8 , and 9 .

(f) UT = Ultrasonic Thermometer 
Test channel instrumentation includes inlet and outlet channel thermocouples, turbine flow meters, and a fuel rod failure detector. A schematic showing IFA-431 in its test channel is shown in Figure 1. IFA-432 is identical except for an ultrasonic thermometer in the upper end of Rod 2.

Data from the instrumentation except for the pressure monitors is automatically taken every 15 min by a data logging system and stored on magnetic tape. The pressure data are obtained manually.

The spacial arrangements of the temperature sensors, fuel, and neutron detectors relative to the reference design axial neutron flux distribution are shown in Figure 2. The location of each test assembly in the reactor core and fuel rod orientations are shown in Figure 3.

The test assemblies are designed so that irradiated fuel rods can be replaced with noninstrumented fresh rods. The original plan called for the removal of three rods from IFA-432 at a burnup of approximately $345 \mathrm{GJ} / \mathrm{kgM}$ (4000 MWd/MTM) and their replacement with fresh noninstrumented rods which wi 11 be irradiated to a goal burnup of $1380 \mathrm{GJ} / \mathrm{kgM}(16,000 \mathrm{MWd} / \mathrm{MTM})$.

\section{FUEL ROD ASSEMBLY}

The fuel pellets were fabricated and characterized at Battelle, Pacific Northwest Laboratories. (4) The cladding was purchased from Sandvik Special Metals Corporation, Kennewick, WA. The pellets and cladding were shipped separately to Halden, Norway, where the instrumented fuel rods were assembled and irradiated.

\section{FUEL RODS}

Each fuel rod was instrumented with two temperature sensors to measure the central fuel temperature and with one cladding elongation sensor to detect the time and extent of pellet-cladding interaction. Al1 of the temperature sensors were thermocouples except for one in IFA-432, which was an ultrasonic thermometer (UT). Three rods in each assembly were each equipped with a pressure transducer to monitor the internal rod pressure. All rods contained $\mathrm{UO}_{2}$ pellets enriched to $10 \mathrm{wt} \%{ }^{235} \mathrm{U}$. The pellets had flat ends and were $12.7 \mathrm{~mm}$ (0.5 in.) 1ong. 


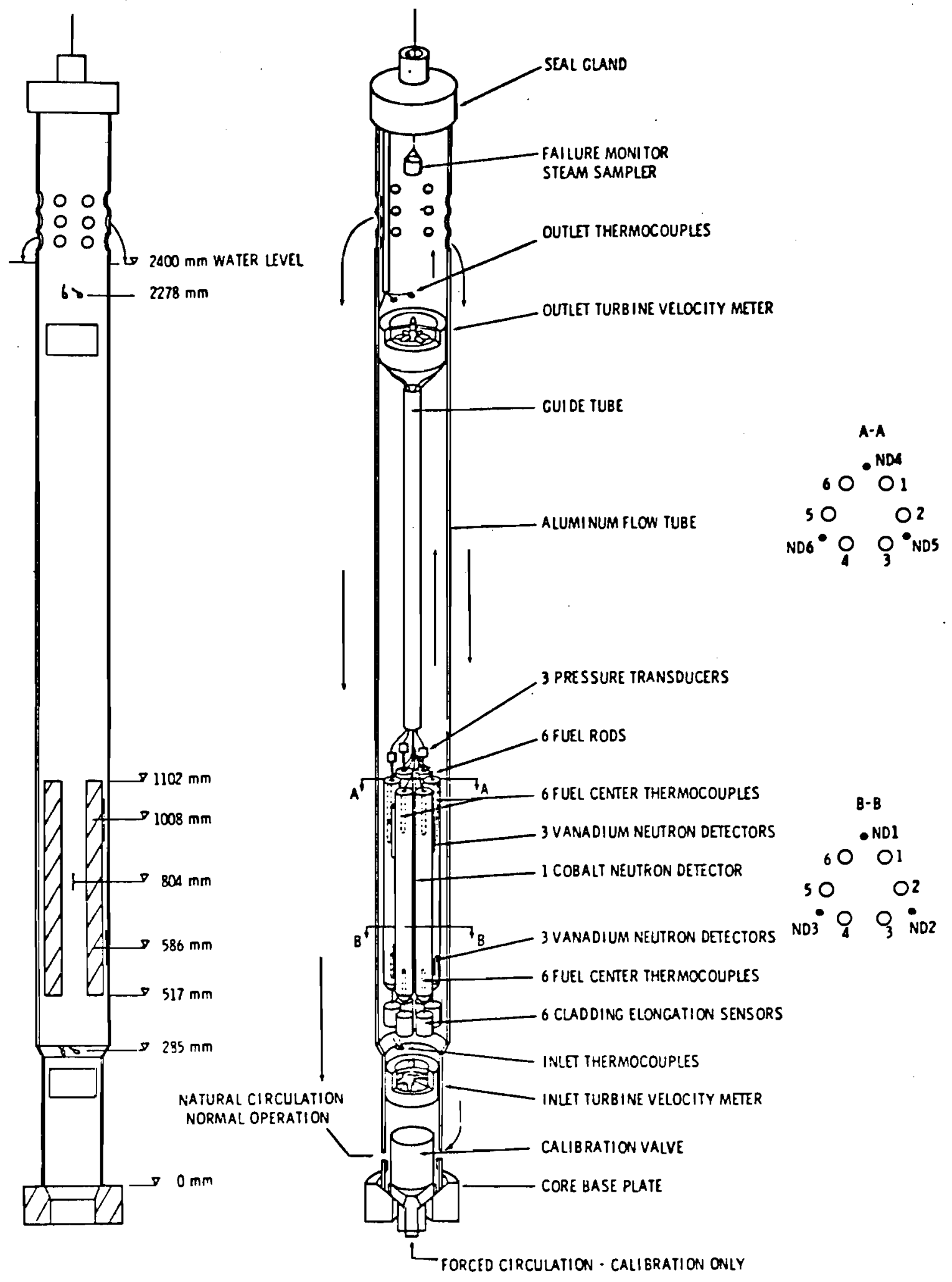

FIGURE 1. Schematic of Instrumented Fuel Assembly--IFA-431 


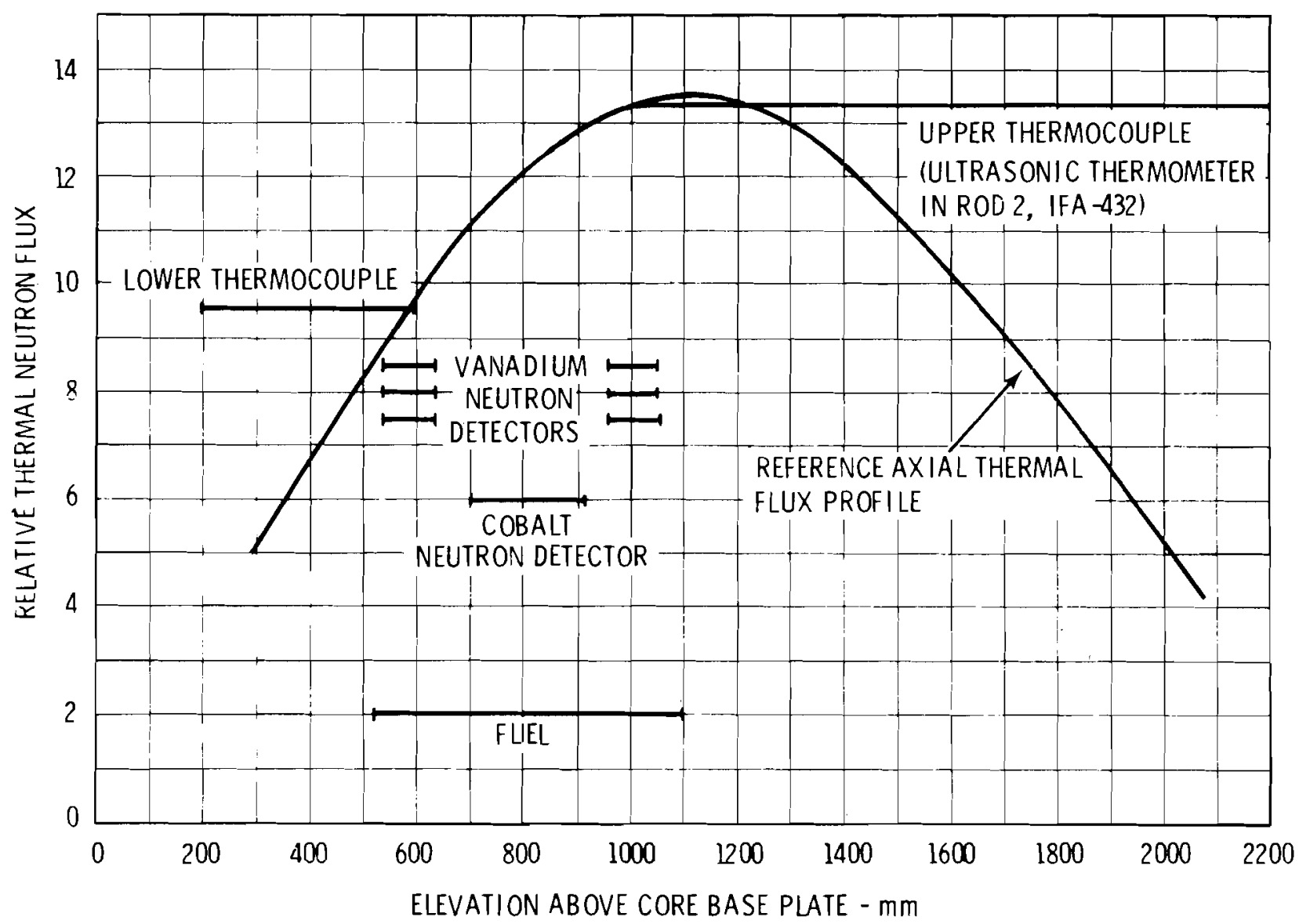

FIGURE 2. Arrangement of Temperature Sensors, Neutron Detectors, and Fuel Relative to Reference Axial Thermal Flux Profile, IFA-437 and IFA-432 


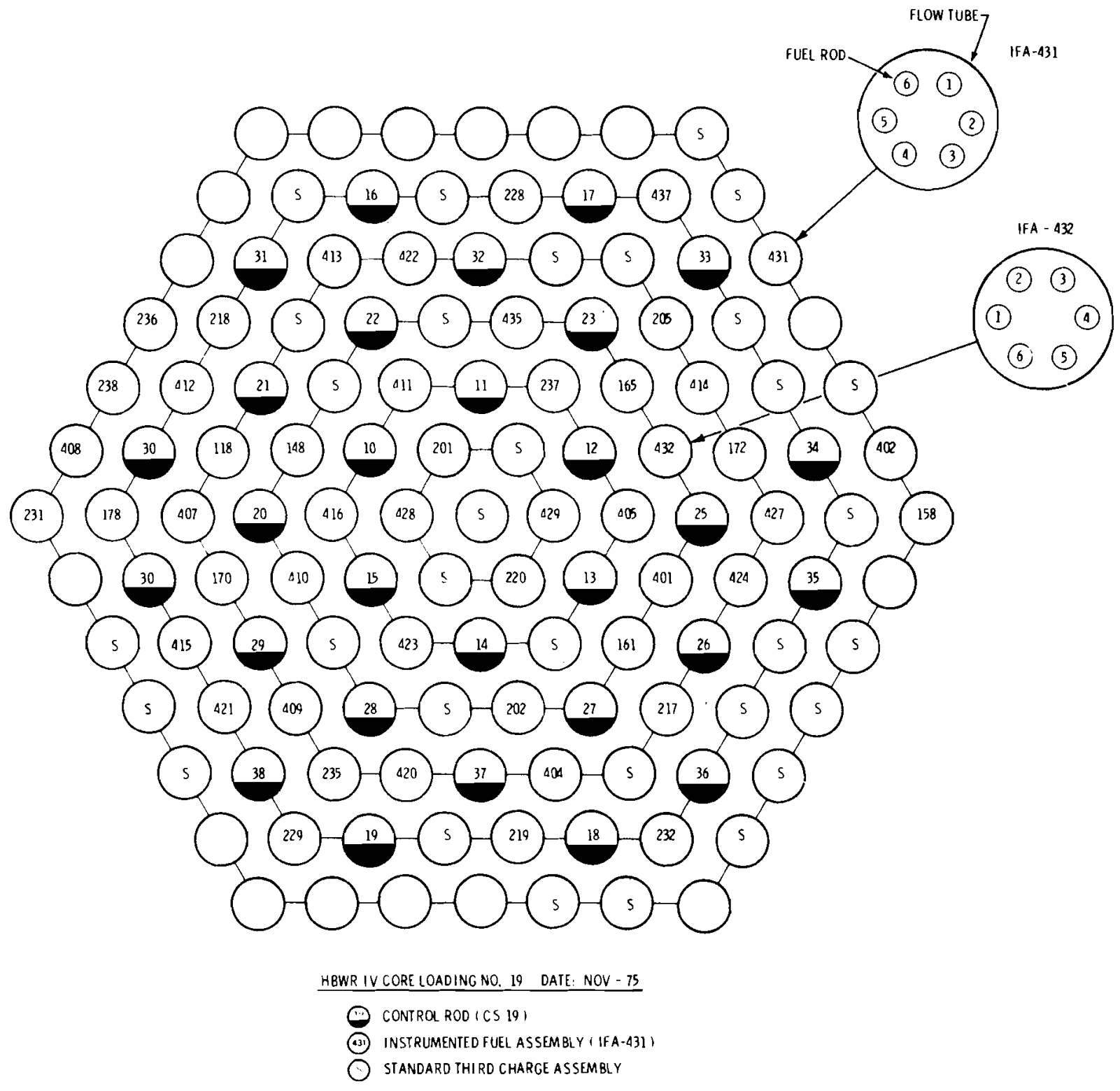

FIGURE 3. Location of Test Assemblies in the Reactor and Fuel Rod Orientation 
Three of the test fuel rods (Rods 1, 5, and 6) were designed to evaluate the effects of fuel stability and density. These rods had $0.229 \mathrm{~mm}$ (9 mils) cold gaps and were backfilled with helium at one atmosphere pressure. Rod 1 was the reference rod and contained $95 \%$ theoretical density (TD) stable fuel. Rods 5 and 6 each contained 92\% TD fuel; however, the fuel in Rod 5 was stable while fuel in Rod 6 was unstable and thus susceptible to densification.

Rod 2 was designed to simulate instantaneous densification. Its design is identical to Rod 1 except for a gap of $0.381 \mathrm{~mm}$ (15 mils).

Rod 3 was designed primarily as an independent check of rod linear heat ratings. This rod is identical to Rod 1 except for a gap of $0.051 \mathrm{~mm}$ (2 mils) in IFA-431 and $0.076 \mathrm{~mm}$ ( $3 \mathrm{mi} \mathrm{s}$ ) in IFA-432. This gap width was selected to provide good pellet-cladding contact at power and yet minimize the potential for cladding failure induced by mechanical interaction. With the temperature gradient across the gap minimized and knowing the measured centerl ine fuel temperature and the calculated cladding temperature, the rod LHR in the assembly can be checked.

Rod 4 was designed to gain an insight into the anomalous thermal behavior of xenon-filled rods and to study the effects of pellet-cladding gap eccentricity. To accomplish the latter, a stack of four pellets near the top of the rod was designed to be centered, and a stack of four pellets near the bottom of the rod was designed to be in contact with the cladding during the irradiation. The temperature within each stack of four pellets was monitored with thermocouples. Rod 4 contained the same type of fuel and had the same gap as Rod 1 but was backfilled with xenon at one atmosphere pressure.

A schematic arrangement of the fuel rods is shown in Figure 4 .

\section{FUEL PELLETS}

All fuel pellets were fabricated and characterized at the Battelle Pacific Northwest Laboratories and shipped to Halden, Norway.

Fuel pellet characterization included analytical and density measurements, and microstructural and thermal studies. 


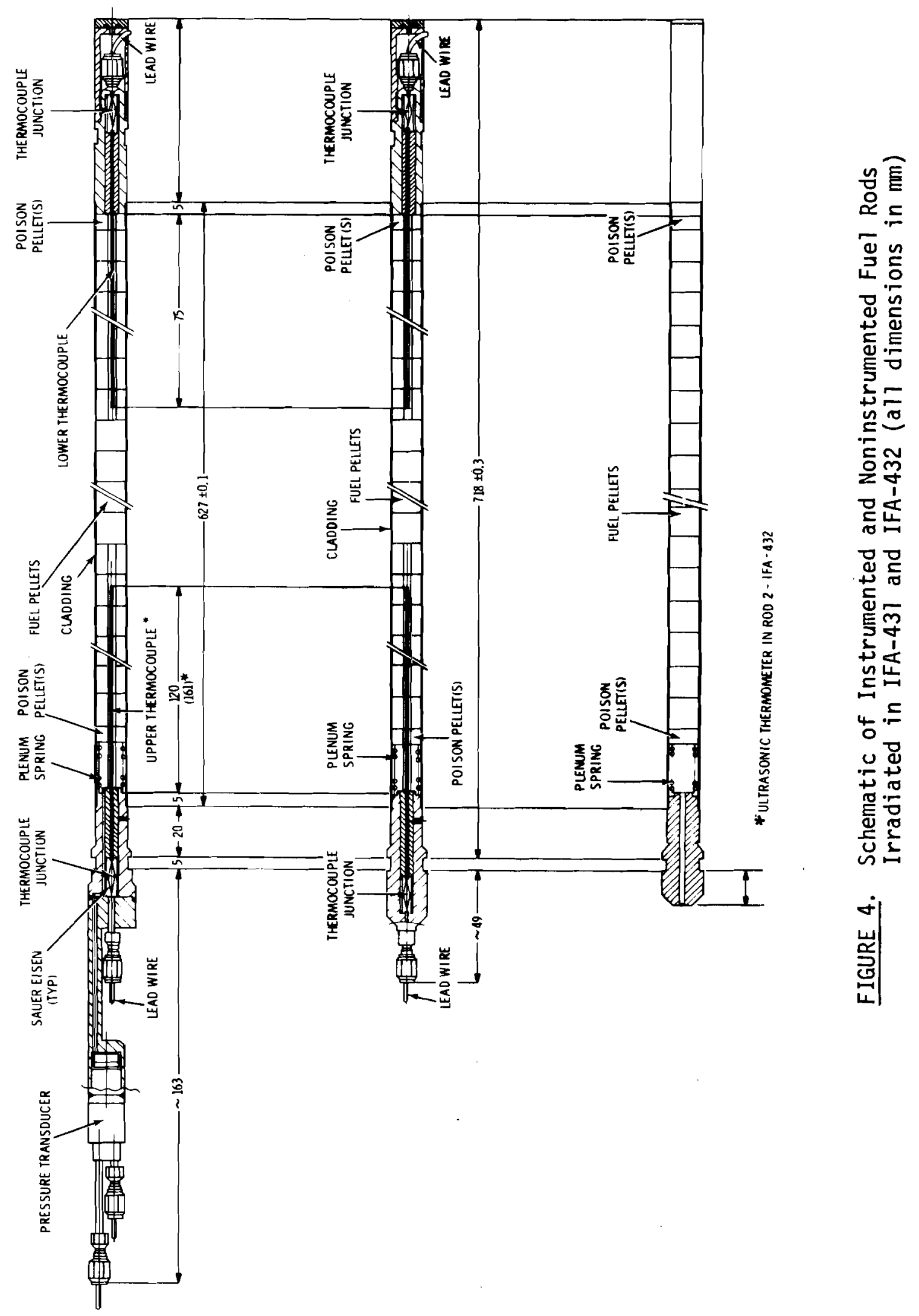


Analytical measurements included weight percent uranium; oxygen-to-uranium ratio; isotopic composition; off-gas; and the level of carbon, nitrogen, fluorine, chlorine, $\mathrm{H}_{2} \mathrm{O}$, and trace impurities.

Density measurements were made using both geometric and liquid immersion techniques. Geometric measurements were based on diameters measured at three locations on each pellet, on lengths at two locations, and on one weight measurement. The liquid immersion technique using water as the suspension media was used to determine bulk density on a selected number of pellets.

Microstructural characterization studies included determining grain size, pore size distribution, and the surface morphology for each type of fuel. Both optical and scanning electron microscopy (SEM) techniques were used.

Thermal studies included measuring the thermal diffusivity of the fuel and performing resintering tests to determine the propensity of the fuel types for densification and to confirm the correlation between irradiation and thermally induced densification. The thermal diffusivity was determined using a laserpulse technique from $100^{\circ} \mathrm{C}\left(212^{\circ} \mathrm{F}\right)$ to $1600^{\circ} \mathrm{C}\left(2912^{\circ} \mathrm{F}\right)$. The thermal conductivity was calculated from the measured thermal diffusivity and from known heat capacities.

The fuel pellets were outgassed at Halden prior to irradiation by drying in air at $125^{\circ} \mathrm{C}\left(255^{\circ} \mathrm{F}\right)$ for $20 \mathrm{hr}$ followed by an 8-to-10 $\mathrm{hr}$ room temperature hold period in vacuum after the loaded pins were placed in the welding chamber. 


\section{DISCUSSION OF RESULTS}

The parameters in this test included pellet-cladding gap size and gap eccentricity, fill gas composition, fuel density and stability, linear heat rating, and burnup.

The cladding elongations which occurred during a number of power ramps were plotted as a function of fuel rod average linear heat rating (ALHR). Fuel rod elongation behavior is based on a comparative analys is of these power ramps. For the sake of clarity, the curves have been relocated on the ordinate and show only relative changes for a specific curve. For most of the curves, only the up ramps are shown.

The effect of test channel coolant boiling power on the elongation detector output is discussed first. The boiling power of the coolant affected the cladding elongation detector outputs during the operating period when IFA-431 was calibrated but did not cause PCI. This is followed by analyses of the effects of gap size, fuel density, and stability on cladding elongations. Final1y, the results of pre- and postirradiation fuel rod measurements are presented and discussed.

This report analyzes the cladding elongation results for the helium-filled rods only. The effects of gap eccentricity and xenon fill gas on fuel rod behavior are presented in another report.

\section{BOILING POWER}

The cladding elongation results for IFA-431 for Ramp B1 differ significantly from those of Ramp $A 1$. Results are shown in Figure 5 . This difference was caused by the procedure which was used to calibrate IFA-431 during Ramp B1.

Ramps $A 1$ and $B 1$ were the first and second successive power ramps for IFA-431.

During Ramp A1, the mode of heat transfer to the coolant was forced circulation. During Ramp B1, the heat transfer was by natural circulation in which the subcooling was changed in order to calibrate the fuel assembly power. The test channel power is determined by varying the subcooling to the channel while maintaining a constant assembly power. (Labeled as CR1 and CR2 on Figure 5. ) 


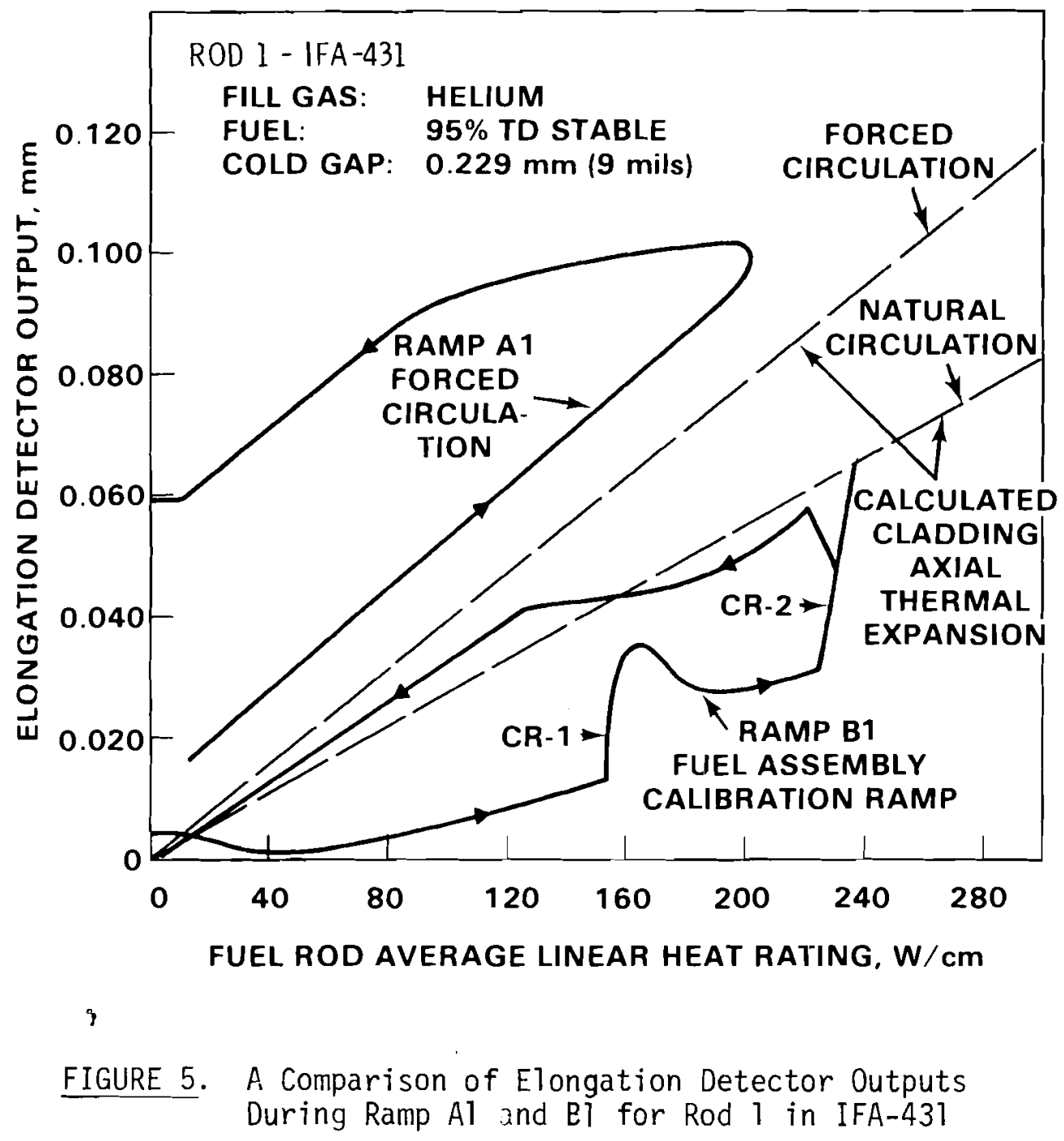


The boiling power is calculated and is plotted as a function of subcooled power. The plot (not shown in this report) is very close to a straight line and by extrapolating to the abscissa the minimum subcooled power required to suppress boiling is determined. This subcooled power is equal to the total channel power. The moderator heating power is calculated and subtracted from the total channel power to give the total assembly power.

The boiling power was changed over a wide range $(0-40 \mathrm{~kW})$ during the calibration procedure. An analysis of the calibration data taken during Ramp B1, indicated that changes in boiling power affected the output of the elongation detectors. As can be seen from Figure 5, the upramp elongation detector output as a function of ALHR for Ramp BI differs significantly from that for Ramp $A 7$ and also from that calculated for the cladding axial thermal expansion for natural circulation. The reason for these significant differences is associated with the changes in boiling power during Ramp BT.

At the essentially constant assembly power during the Ramp $B 1$ calibration runs (CRI and CR2), the transition from nonboiling to boiling surface heat transfer coefficient causes a reduction in average cladding temperature, thus resulting in a decrease in cladding length. Also, at low boiling powers mixing in the test channel is poor. Poor mixing results in coolant temperatures which are higher near the fuel rods than those near the test channel. As the boiling power increases, mixing improves and the coolant temperatures near the fuel rods decrease and those near the channel increase. This results in an additional reduction in cladding temperatures and also an increase in stay rod temperatures and in stay rod length. A schematic sketch showing the relationship of the stay rods, elongation detectors, and fuel rods is shown in Figure 6. An increase in stay rod temperatures causes a decrease in elongation detector output.

The effect on elongation detector output at 0 boiling power (Ramp Al) and with increasing boiling power (Ramp B1) is shown in Figure 7 . This figure is a plot of data taken from Ramp $A 1$ at $160 \mathrm{~W} / \mathrm{cm}(4.9 \mathrm{~kW} / \mathrm{ft})$ and an elongation detector output of $0.078 \mathrm{~mm}$ ( $3 \mathrm{mi} 1 \mathrm{~s}$ ), and from Ramp B1, Calibration Run 1, in which the fuel rod average linear heat rating was maintained between $155 \mathrm{~W} / \mathrm{cm}$ $(4.7 \mathrm{~kW} / \mathrm{ft}$ and $158 \mathrm{~W} / \mathrm{cm}(4.8 \mathrm{~kW} / \mathrm{ft})$. This figure shows that at a fue 1 rod 


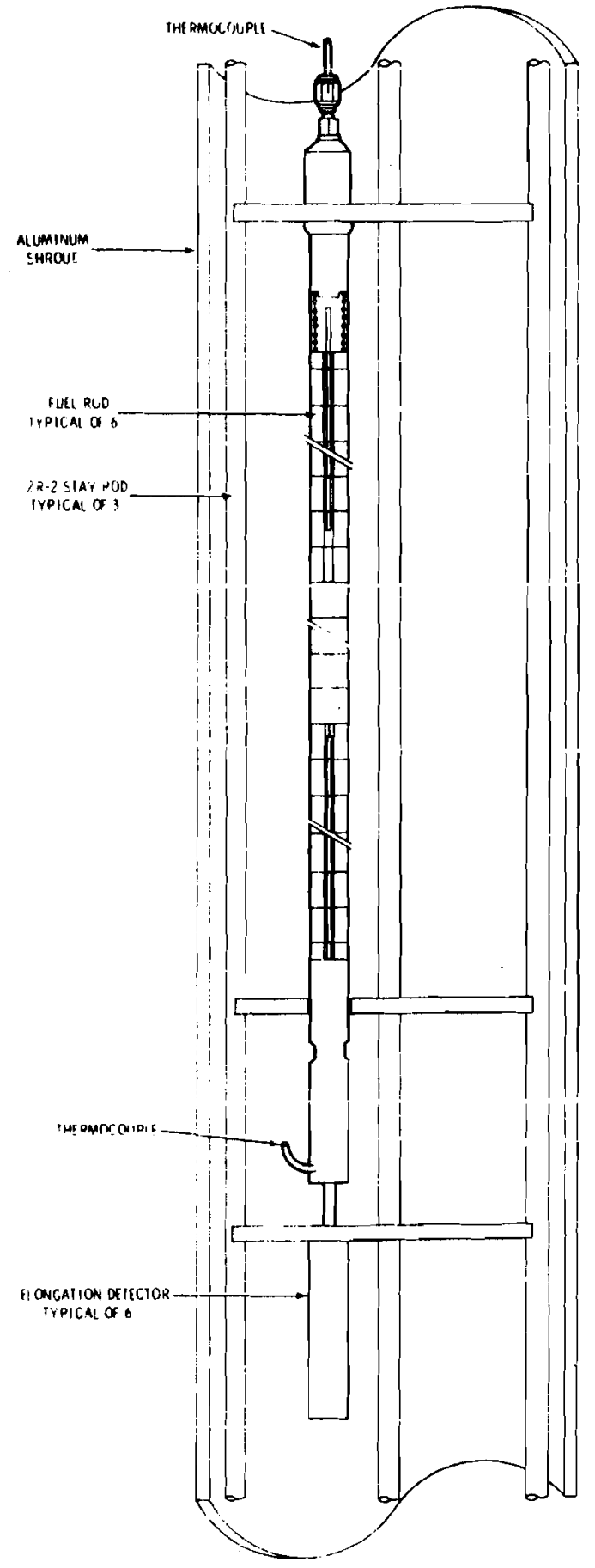

FIGURE 6. Schematic Arrangement of Fuel Rod Elongation Measurement System 


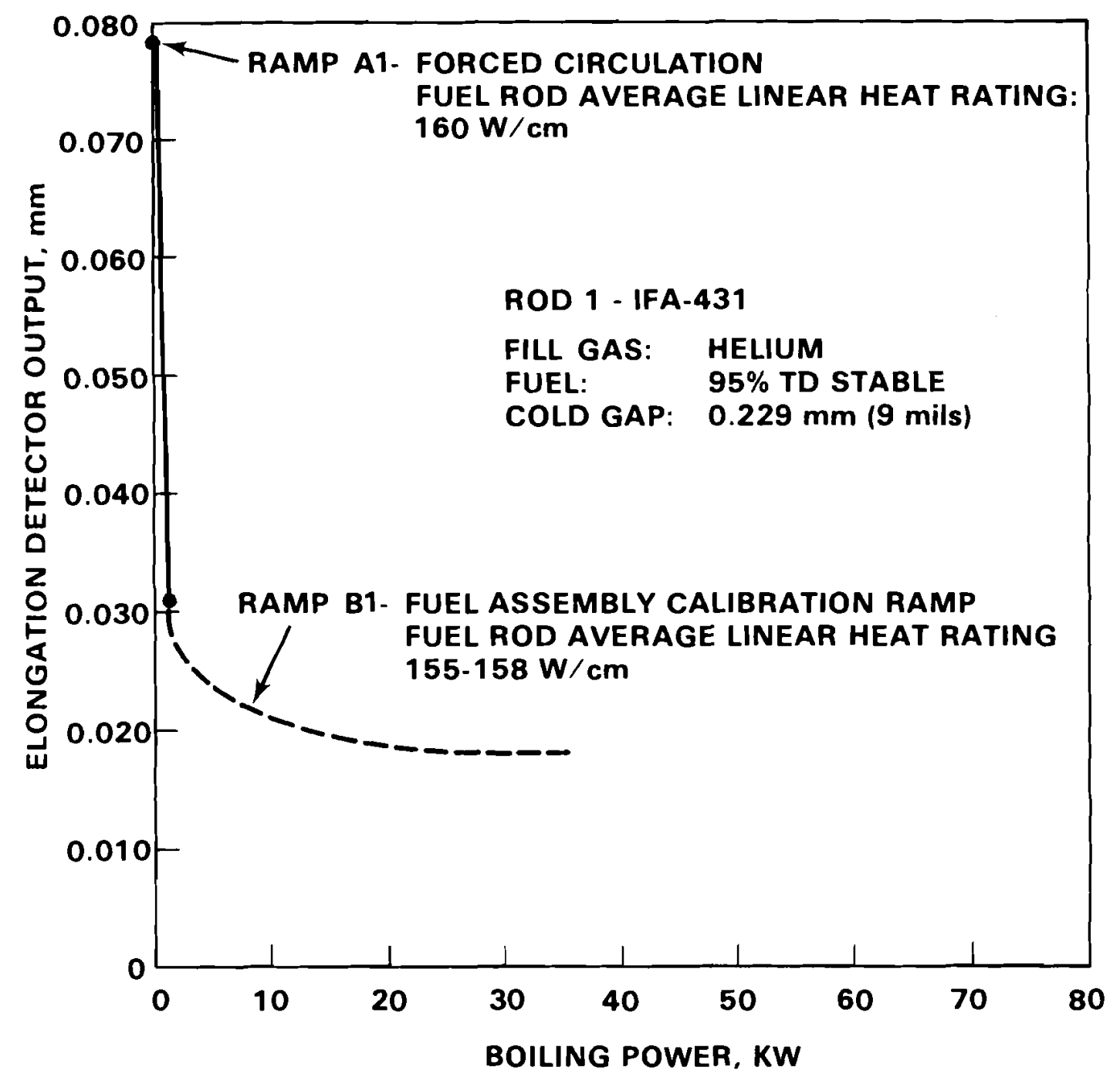

FIGURE 7. Elongation Detector Output as a Function of Boiling Power at Constant Fuel Rod Linear Heat Rating for IFA-431 
average linear heat rating of $155-160 \mathrm{~W} / \mathrm{cm}(4.7-4.9 \mathrm{~kW} / \mathrm{ft})$ the elongation detector outputs decreased from $0.078 \mathrm{~mm}(3 \mathrm{mi} 1 \mathrm{~s}$ ) (Ramp $A 1,0$ boiling power) to $0.018 \mathrm{~mm}$ ( $0.7 \mathrm{mi} 1$ ) (Ramp B1, $35 \mathrm{~kW}$ boiling power). Calculations predict that an increase of stay rod average temperature of $15^{\circ} \mathrm{C}\left(27^{\circ} \mathrm{F}\right)$ relative to the cladding average temperature would produce the observed change in elongation detector output. A relative temperature change of $15^{\circ} \mathrm{C}\left(27^{\circ} \mathrm{F}\right)$ under these circumstances is not unreasonable.

The ramps for Rods $1,2,5$, and 6 are shown in Figure 8 for comparison purposes. The slope for Rod 5 is greater than the others because of PCI occurring in this rod. The ramp for Rod 3 for the calibration run is shown in Figure 9. This ramp is not significantly perturbed by the calibration runs because of the strong PCI in this rod.

The same type of analysis could not be performed on IFA-432 data because a failed calibration valve prohibited a similar calibration of the assembly. Fortunately, the thermal design of IFA-432 was similar to IFA-431 and other instrumentation could be used for calibration.

In evaluating the initiation of PCI in fuel rods in which cooling was by natural circulation, comparison is made to the slope of Rod 2 in IFA-431 before the refueling shutdown during which PCI was not observed. This slope, rather than a calculated slope, was judged to be the better measure of cladding free axial thermal expansion.

\section{GAP WIDTH}

Sma11 Gap Rods: Rod 3

One rod in each assembly, Rod 3, was designed with a smal1 gap, $0.051 \mathrm{~mm}$ (2 mils) in IFA-431 and $0.076 \mathrm{~mm}(3 \mathrm{mils})$ in IFA-432, to assure good pelletcladding contact at power. Each rod contained 95\% TD stable fuel pellets.

The pattern of elongation behavior of the rods was similar in nature; however, there were differences in detail which are attributed to the different gap widths. The results for these two rods are shown in Figures 10 and 11 . 


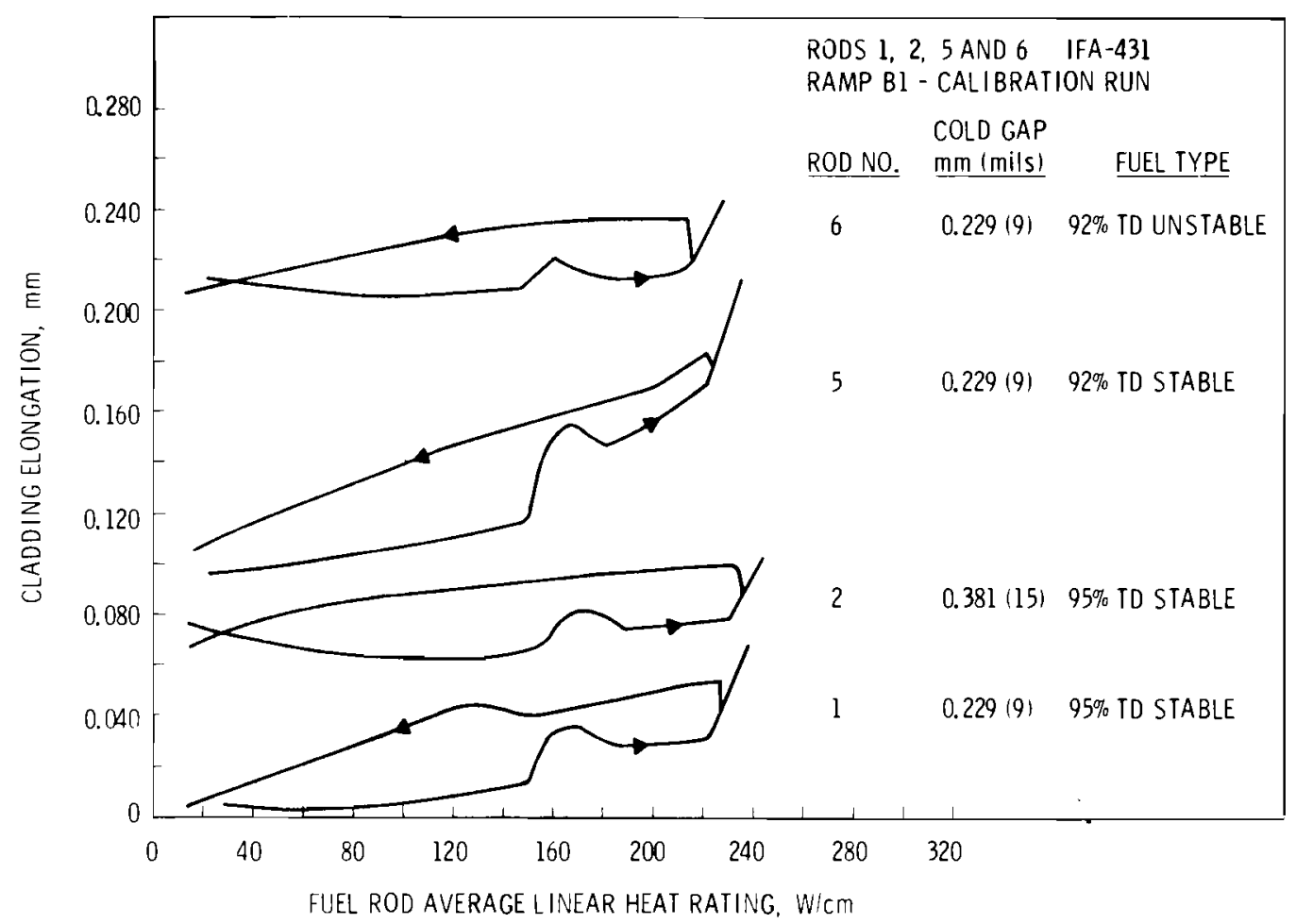

FIGURE 8. Ramp for Rods 1, 2, 5, and 6 During Calibration Run, Ramp B1-IFA-431 (note: The curves have been relocated on the ordinate and show only relative changes for a specific curve.)

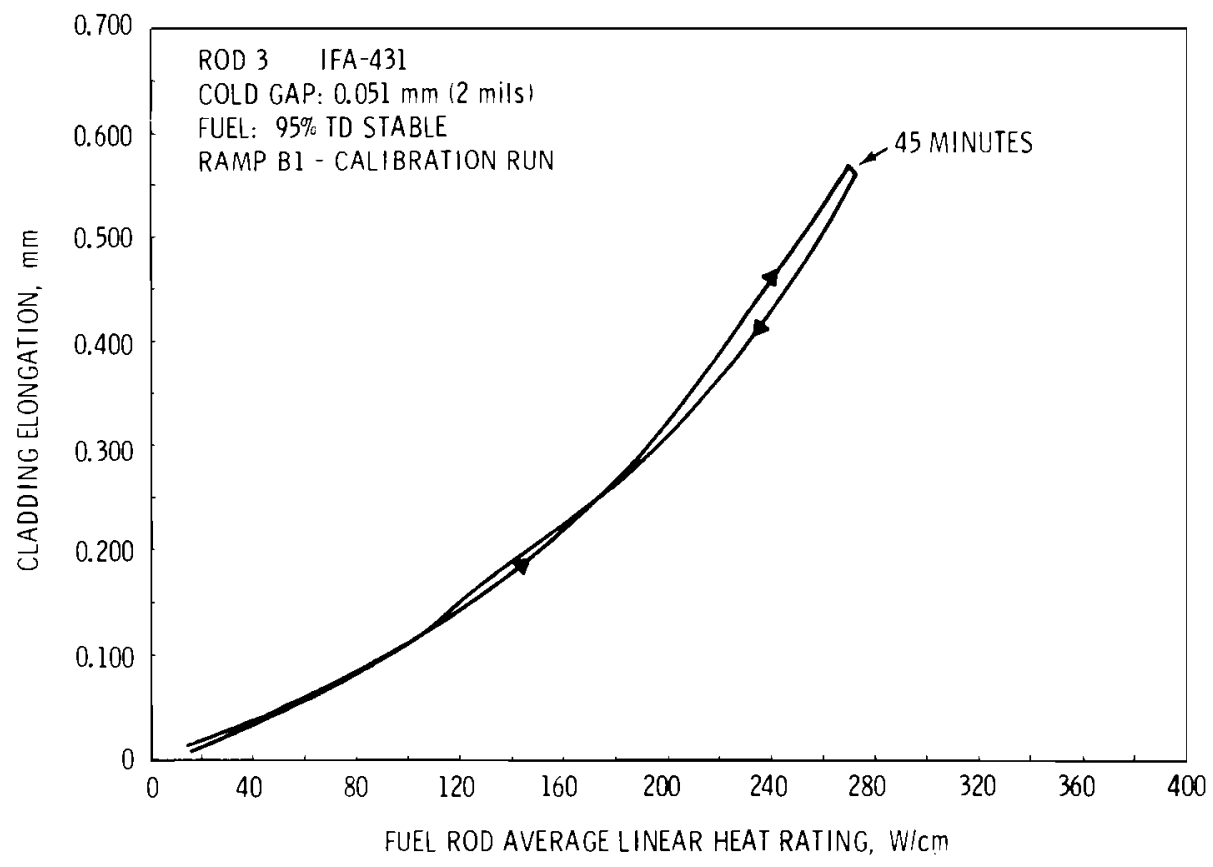

FIGURE 9. Ramp for Rod 3 During Calibration Run, Ramp B1-IFA-431 

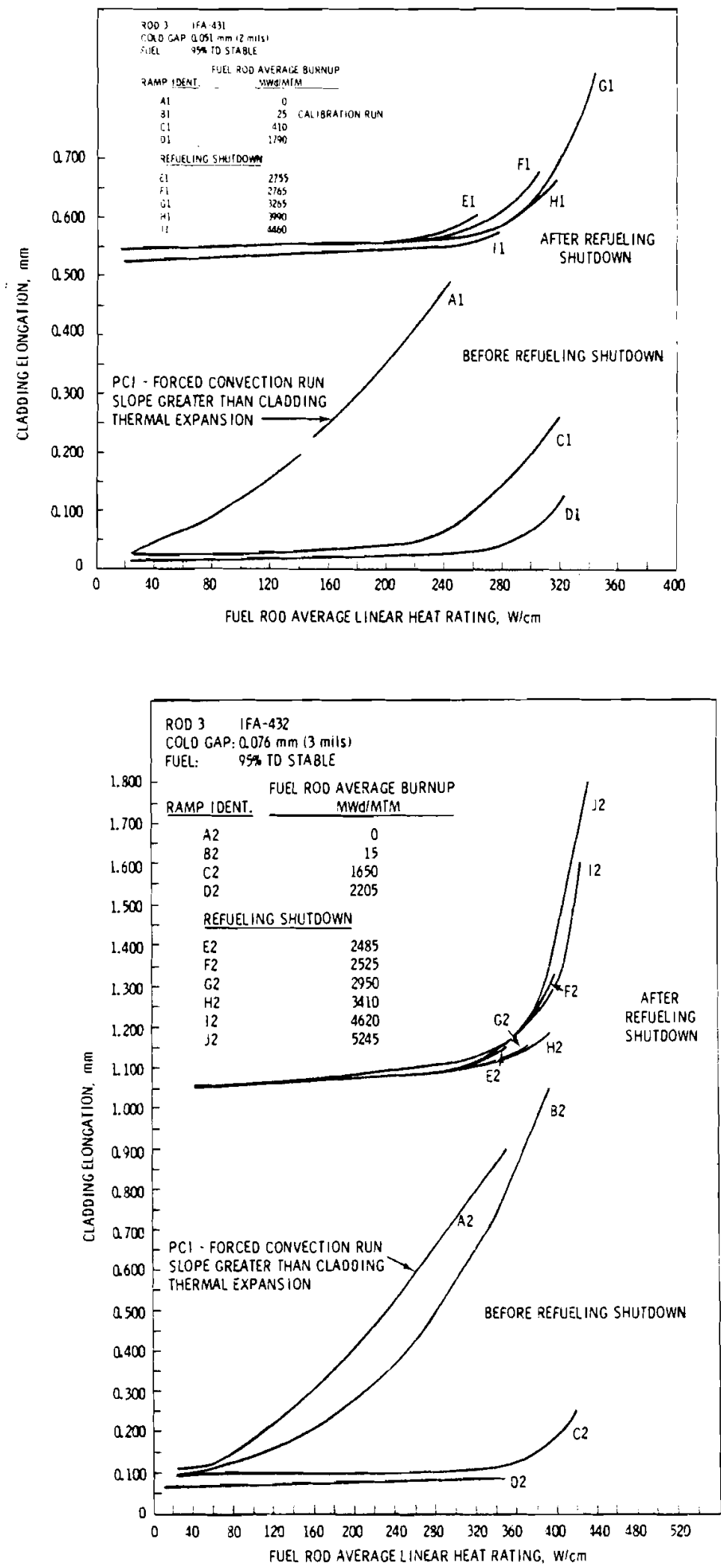

FIGURE 10. Fuel Rod Elongations for Rod 3, IFA-431 (note: The curves have been relocated on the ordinate for comparison purposes and show only relative changes for a specific curve.)
FIGURE 11. Fuel Rod Elongations for Rod 3, IFA-432 (note: The curves have been relocated on the ordinate for comparison purposes and show only relative changes for a specific curve.) 
Both rods showed strong PCI aimost immediately after the first power ramp started (Ramps $A 1$ and $A 2$ ). It appears that PCI was initiated in IFA-431 near $30 \mathrm{~W} / \mathrm{cm}(1 \mathrm{~kW} / \mathrm{ft})$ but was not initiated in IFA-432 until $60 \mathrm{~W} / \mathrm{cm}(2 \mathrm{~kW} / \mathrm{ft})$. This difference is attributed to the larger gap, $0.076 \mathrm{~mm}$ ( $3 \mathrm{mils}$ ), in Rod 3 in IFA-432 compared to a $0.051 \mathrm{~mm}$ ( $2 \mathrm{mils}$ ) gap in IFA-431. It is postulated that pellet cracking and relocation of the pellet fragments to the cladding took place shortly after startup in these two rods; however, because of the larger gap in IFA-432, a slightly longer period of time was required before the pellet fragments relocated to the cladding. Once the pellet fragments relocated to the cladding, the frictional forces between the contact areas resulting from the radial thermal expansion of the pellets were immediately increased to the point where axial thermal expansion of the pellet stack caused the cladding elongation to exceed that resulting from free thermal expansion.

Other differences which are attributed to the different gap widths are as follows:

- After PCI was initiated in Ramps A1 and A2, the average slope for Rod 3 in IFA-431 was approximate1y 10\% greater than that in IFA-432.

- During the irradiation period before the refueling shutdown and at the same LHR, the elongations resulting from PCI for Rod 3 in IFA-431 were greater than those in IFA-432.

- During the irradiation period after the refueling shutdown, PCI was initiated in IFA-431 at approximately $220 \mathrm{~W} / \mathrm{cm}(6.7 \mathrm{~kW} / \mathrm{ft}$ ) (Ramp E1) and in IFA-432 at approximately $300 \mathrm{~W} / \mathrm{cm}$ (9.1 kW/ft) (Ramp E2).

Before the refueling shutdown and at fixed 1 inear heat ratings for each ramp, the cladding elongations resulting from PCI decreased in both assemblies. This is attributed to the formation of axial gaps between pellets or groups of pellets.

Large Gap Rods: Rod 2

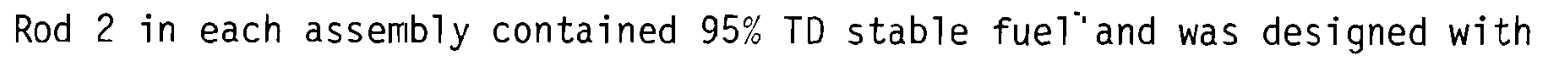
a large gap, $0.381 \mathrm{~mm}$ (15 mils), to simulate instantaneous densification. 
Rod 2 in IFA-431 behaved in a different manner than in IFA-432. The elongation behavior for these rods is shown in Figures 12 and 13 .

In IFA-431 and before the refueling shutdown, no PCI was observed in Rod 2 . After the refueling shutdown, PCI was observed during Ramps F1 and G1 with PCI occurring at a higher ALHR in Gl than in Fl indicating the formation of gaps between pellets.

In IFA-432 and before the shutdown, PCI was not observed in Ramp A2 but was observed to occur in Ramps B2, C2, and D2 at approximately the same ALHR of $160 \mathrm{~W} / \mathrm{cm}(4.9 \mathrm{~kW} / \mathrm{ft})$. After the refueling shutdown, PCI was observed to occur at progressively lower linear heat ratings with increasing cladding elongations during subsequent power ramps. This cannot be attributed to the closing of axial gaps between pellets because the behavior of this rod before the refueling shutdown did not indicate the formation of axial gaps. An explanation of what might have happened in this rod in IFA-432 is given in the following paragraphs.

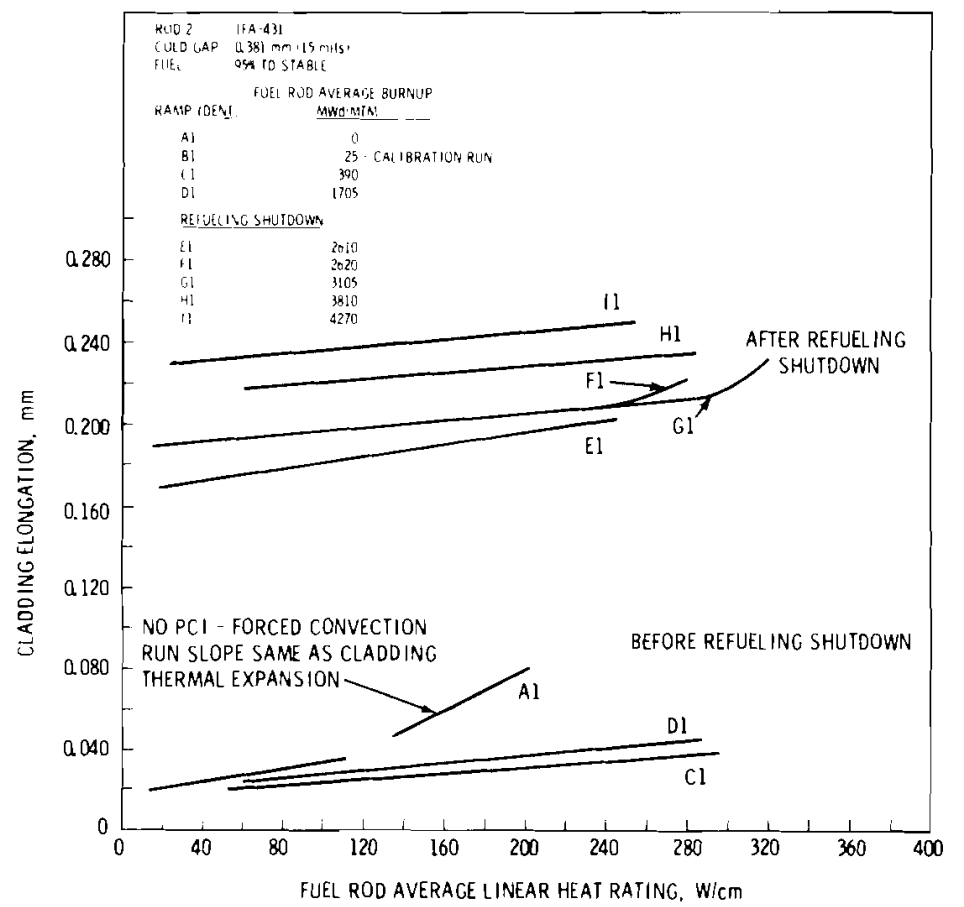

FIGURE 12. Fuel Rod Elongations for Rod 2, IFA-431 (note: The curves have been relocated on the ordinate for comparison purposes and show only relative changes for a specific curve.) 


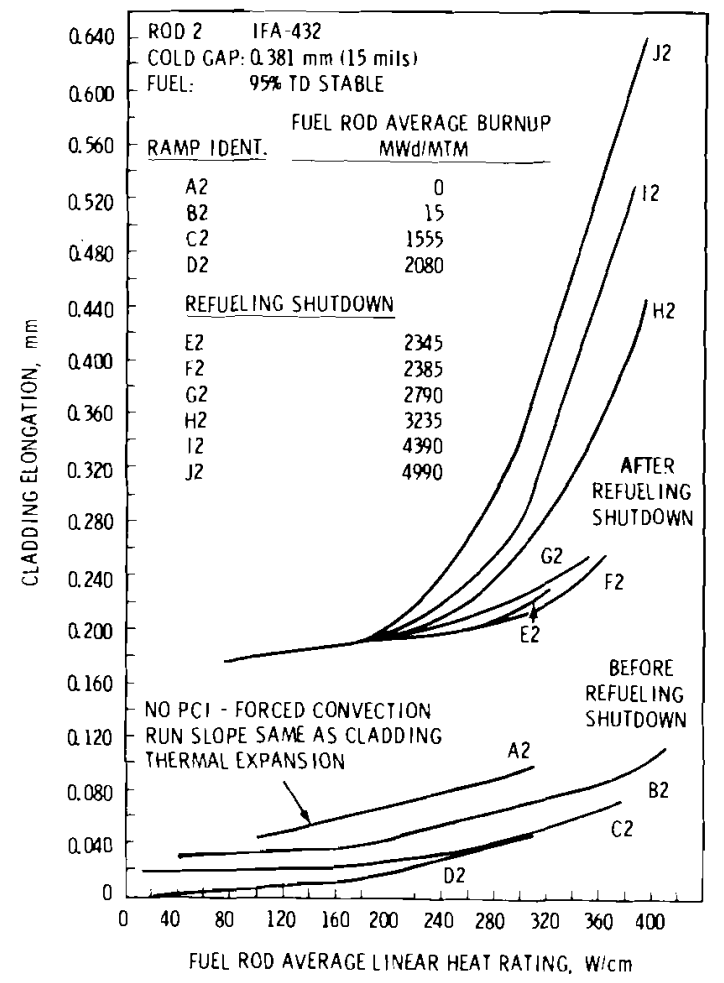

FIGURE 13. Fuel Rod Elongations for Rod 2, IFA-432 (note: The curves have been relocated on the ordinate for comparison purposes and show only relative changes for a specific curve.)

The assembled fuel rods start their journey with the fuel pellets in contact with the cladding. The pellets are loaded into the cladding, the compression springs installed, and the closure welds made while the rods are in the horizontal position. By the time the fuel rods reach the reactor and are loaded, most pellets probably are still in contact with the cladding.

During the first ramp to power, those pellets in contact with the cladding will remain so because of the axial spring load on the stack. It is postulated that during the startup of Ramp B2, a pellet fragment fell into the gap as is shown in Figure 14. As the fuel rod LHR increased, thermal expansion of the pellet fragments increased the frictional force between the contact areas until the axial thermal expansion of the pellet stack caused the cladding to elongate. During Ramps $C 2$ and $D 2$, the fragment remained in essentially the 


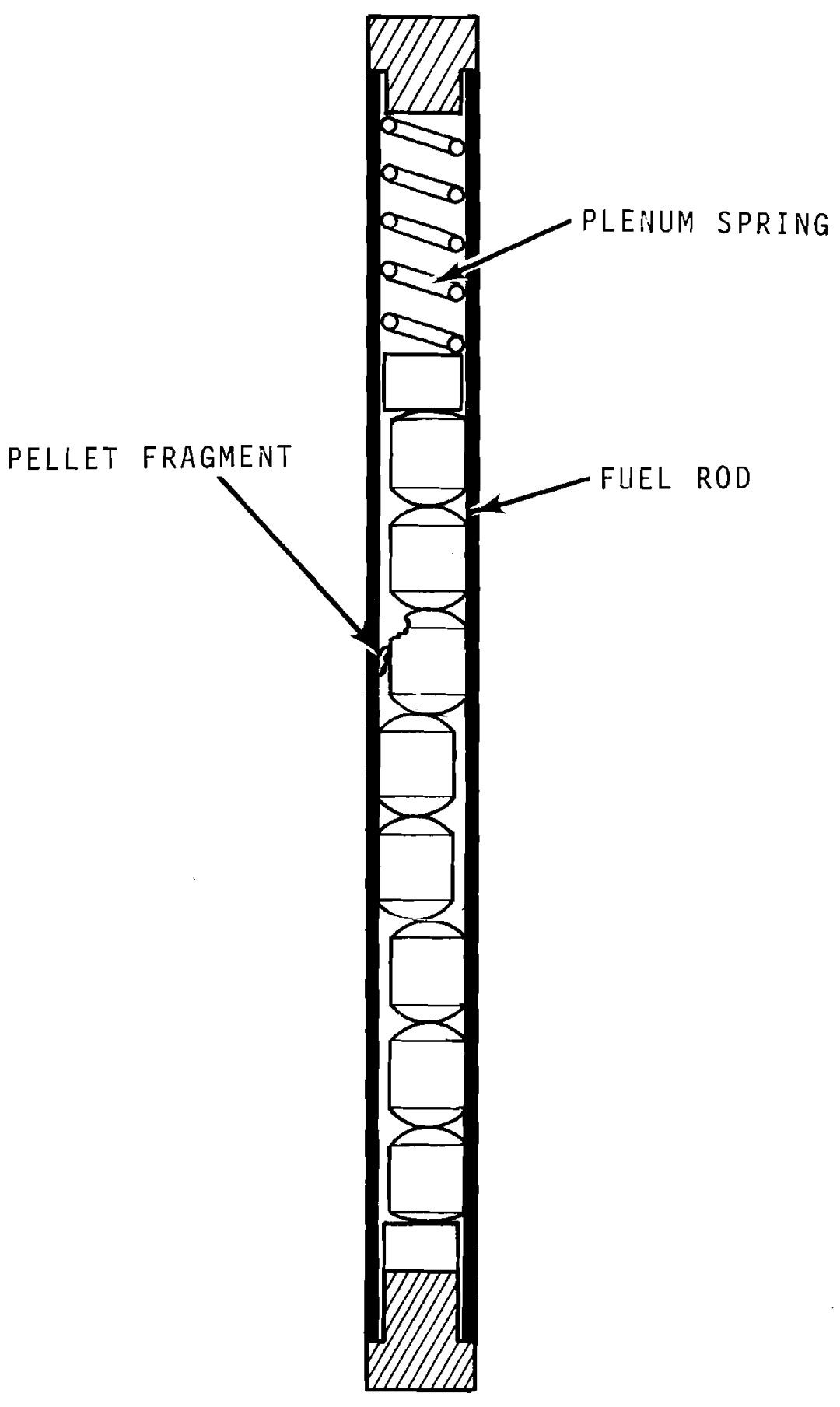

FIGURE 14. Fuel Stack with Displaced Pellet Fragment 
same iocation. After the refueling shutdown and during subsequent ramps, additional fragments may have fallen into the gap and lodged at progressively higher locations leading to additional PCI and increased cladding elongations at the same ALHR. Why Rod 2 in IFA-432 behaved differently than Rod 2 in IFA-431 is not clear. IFA-432 operated at higher powers than IFA-431 and at ramp rates which were generally higher, sometimes by a factor of three, than those in IFA-431.

Sma11, Intermediate, and Large Gap Rods: Rods 1, 2, and 3

Three rods in each assembly contained $95 \%$ TD stable fuel. One rod had a smal1 gap (Rod 3), $0.051 \mathrm{~mm}(2 \mathrm{mils}$ ) in IFA-431 and $0.076 \mathrm{~mm}$ (3 $\mathrm{mi} 1 \mathrm{~s}$ ) in IFA-432; an intermediate gap (Rod 1), $0.229 \mathrm{~mm}(9 \mathrm{mi} 1 \mathrm{~s})$; and a large gap (Rod 2), $0.381 \mathrm{~mm}(15 \mathrm{mils})$. The behavior of these rods is shown in Figures 10, 12, and 15 for IFA-431 and in Figures 11, 13, and 16 for IFA-432. An interesting observation from a comparison of these figures is that regardless of gap size, PCI occurred at some time in all rods and that at a burnup of approximately $260 \mathrm{GJ} / \mathrm{kgM}$ (3000 MWd/MTM), Ramps G1 and G2, PCI occurred in

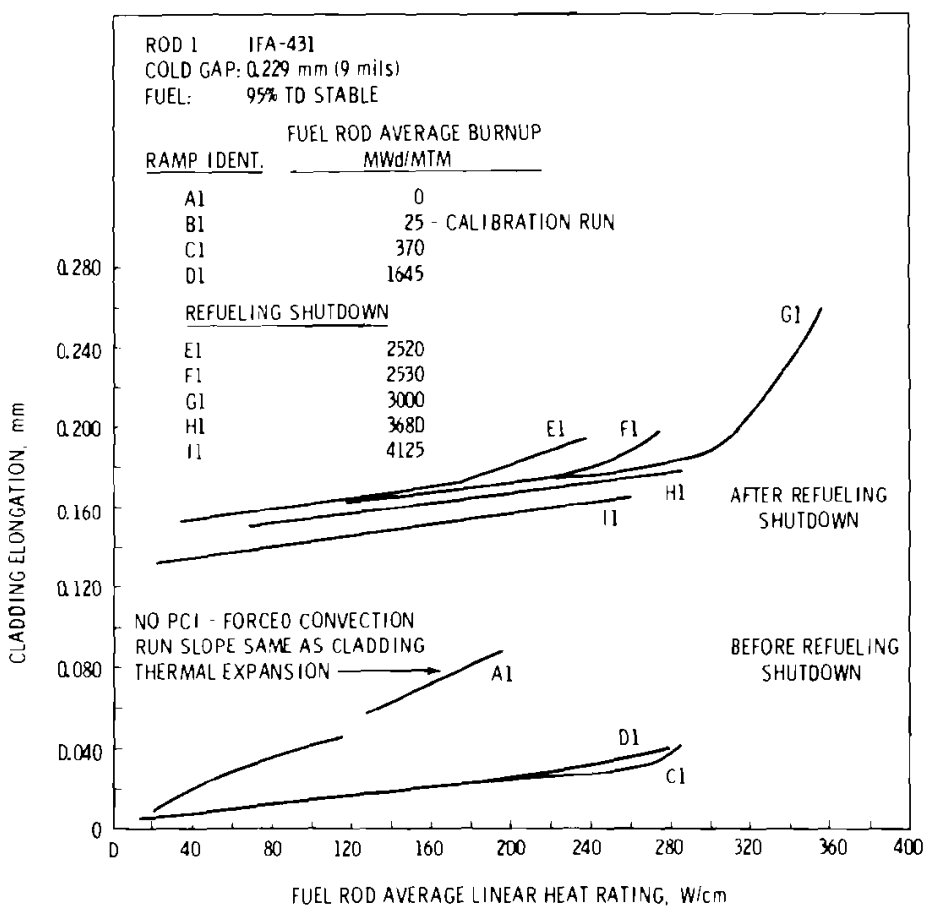

FIGURE 15. Fuel Rod Elongations for Rod 1, IFA-431 (note: The curves have been relocated on the ordinate for comparison purposes and show only relative changes for a specific curve.) 


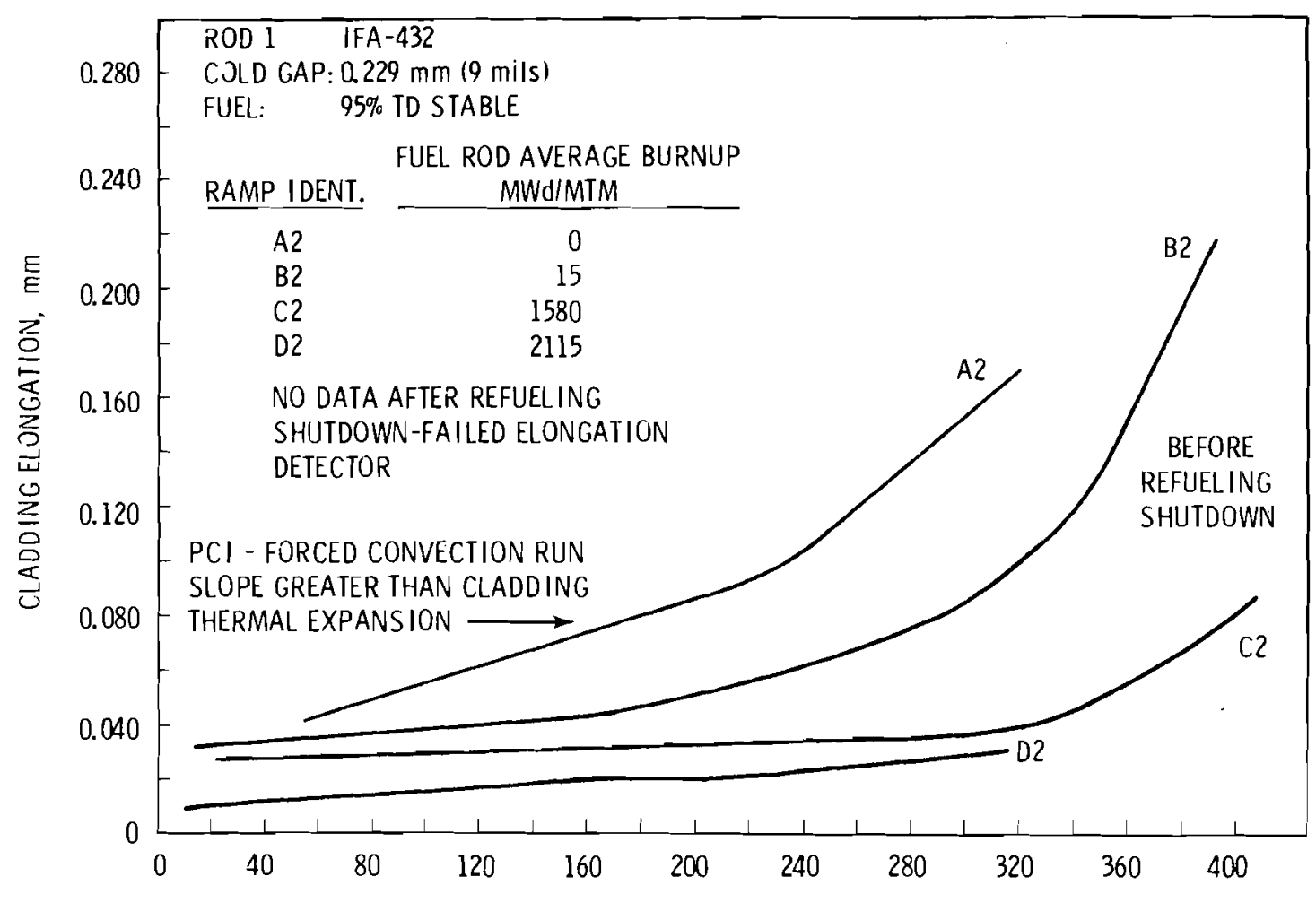

FUEL ROD AVERAGE LINEAR HEAT RATING, W/cm

FIGURE 16. Fuel Rod Elongations for Rod 1, IFA-432 (note: The curves have been relocated on the ordinate for comparison purposes and show only relative changes for a specific curve.)

a11 of these rods between $260 \mathrm{~W} / \mathrm{cm}(7.9 \mathrm{~kW} / \mathrm{ft})$ and $290 \mathrm{~W} / \mathrm{cm}(8.8 \mathrm{~kW} / \mathrm{ft})$. Exceptions to this observation are Rod 2 in IFA-432 which was discussed above and Rod 1 in IFA-432 after the refueling shutdown when the elongation detector was inoperable.

The results of postirradiation examination (PIE) showed that a permanent diametral strain of approximately $0.1 \%$ occurred in Rod 3 but no permanent strain occurred in Rods 1 and 2 in IFA-431. The results of PIE are presented in the Pre- and Postirradiation Measurements Section.

FUEL DENSITY AND STABILITY: Rods 1,5 , and 6

Fuel Rods 1, 5, and 6 were designed to obtain information concerning the effects of density and stability on fuel rod behavior. These rods all had $0.229 \mathrm{~mm}$ (9 mils) gaps. Rod 1 contained 95\% theoretical density (TD) stable 
fuei. Rods 5 and 6 each contained $92 \%$ î̀ fuel; however, the fue 1 in Rod 5 was stable while that in Rod 6 was unstable and thus susceptible to densification.

The elongation behavior of these three rods in IFA-431 was similar in nature to the companion rods in IFA-432; the major difference was greater elongations in IFA-432 because of its higher power level. The results for these rods are presented in Figure 15, 17, and 19 for IFA-431 and 16, 18, and 20 for IFA-432.

The rods with low density stable fuel, Rod 5, behaved similarly in both assemblies, but showed greater PCI than either Rods 1 or 6 . The greater occurrence of PCI in Rod 5 in both assemblies is attributed to the lower fuel thermal conductivity in the $92 \%$ TD stable fuel contained in this rod. Thermal conductivity measurements on unirradiated fuel of this type ${ }^{(4)}$ showed conductivities which were significantly lower than those in the other fuel types. The average thermal conductivity in the $92 \%$ TD stable fuel was $17 \%$ less than that in the 95\% TD fuel and $8 \%$ less than that in the $92 \%$ TD unstable fuel. Apparently the lower thermal conductivity caused pellet cracking and expansion to result in PCI at an ALMR significantly less than that in Rods 1 and 6 .

In IFA-431 and before the refueling shutdown, the behavior of Rods 1 and 6 was similar (Figures 15 and 19). PCI was observed in Rod 1 at $270 \mathrm{~W} / \mathrm{cm}$ $(8.2 \mathrm{~kW} / \mathrm{ft}$ ) (Ramp $\mathrm{Cl}$ ). PCI was not observed in Rod 6 probably because of the relatively low maximum ALHR and densification. As discussed above, strong PCI was observed in Rod 5. After the shutdown, the behavior of these intermediate gap rods was remarkably similar in nature and PCI was observed during the first ramp to power (Ramp El) in each rod at approximately $170 \mathrm{~W} / \mathrm{cm}(5.2 \mathrm{~kW} / \mathrm{ft})$. During subsequent Ramps (FI and G1), PCI occurred at higher ALHR's. The occurrence of PCI at progressively higher ALHR's during subsequent ramps is attributed to the formation of axial gaps between pellets or groups of pellets.

It is interesting to compare in more detail the behavior of these three rods in IFA-431 before the shutdown with that after the shutdown. In Rod 5 , PCI was observed during the first power ramp (Ramp A1) to occur at less than $100 \mathrm{~W} / \mathrm{cm}(3.0 \mathrm{~kW} / \mathrm{ft})$ and also at approximately $200 \mathrm{~W} / \mathrm{cm}(6.1 \mathrm{~kW} / \mathrm{ft}$ ) (Ramps Cl 


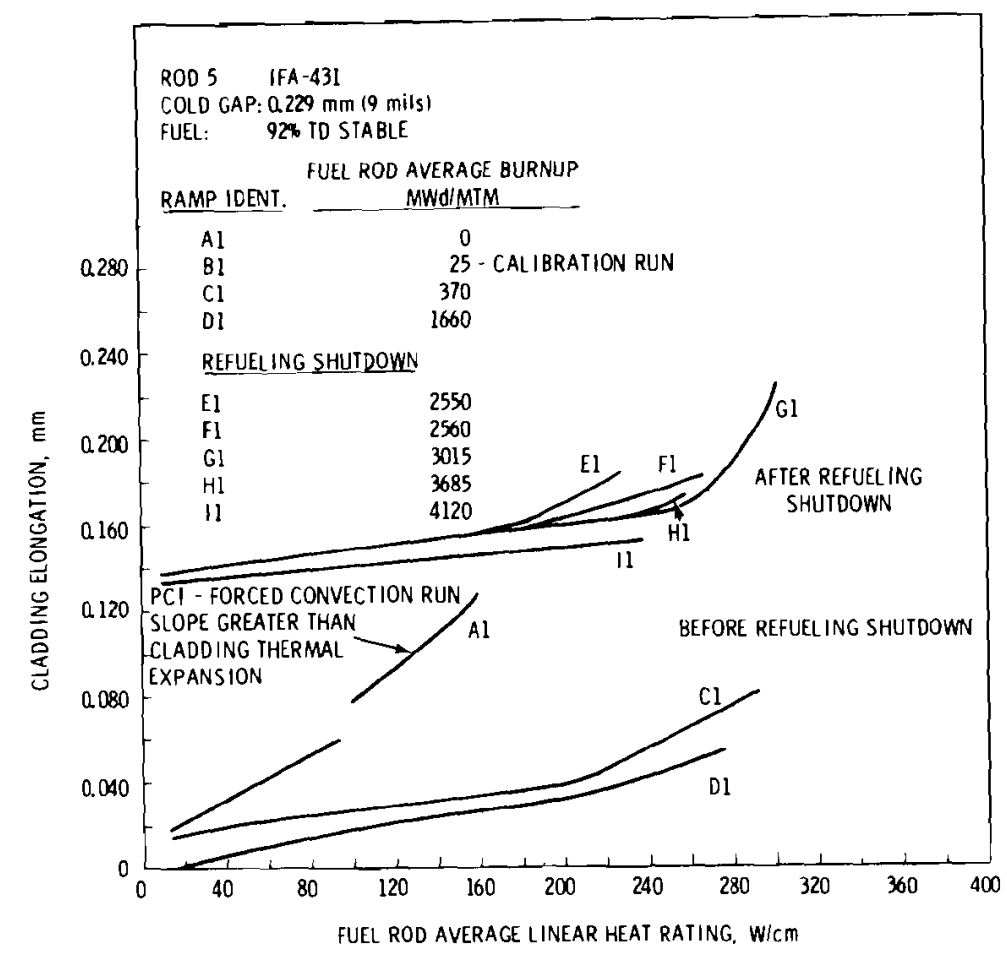

FIGURE 17. Fuel Rod Elongations for Rod 5, IFA-431 (note: The curves have been relocated on the ordinate for comparison purposes and show only relative changes for a specific curve.)

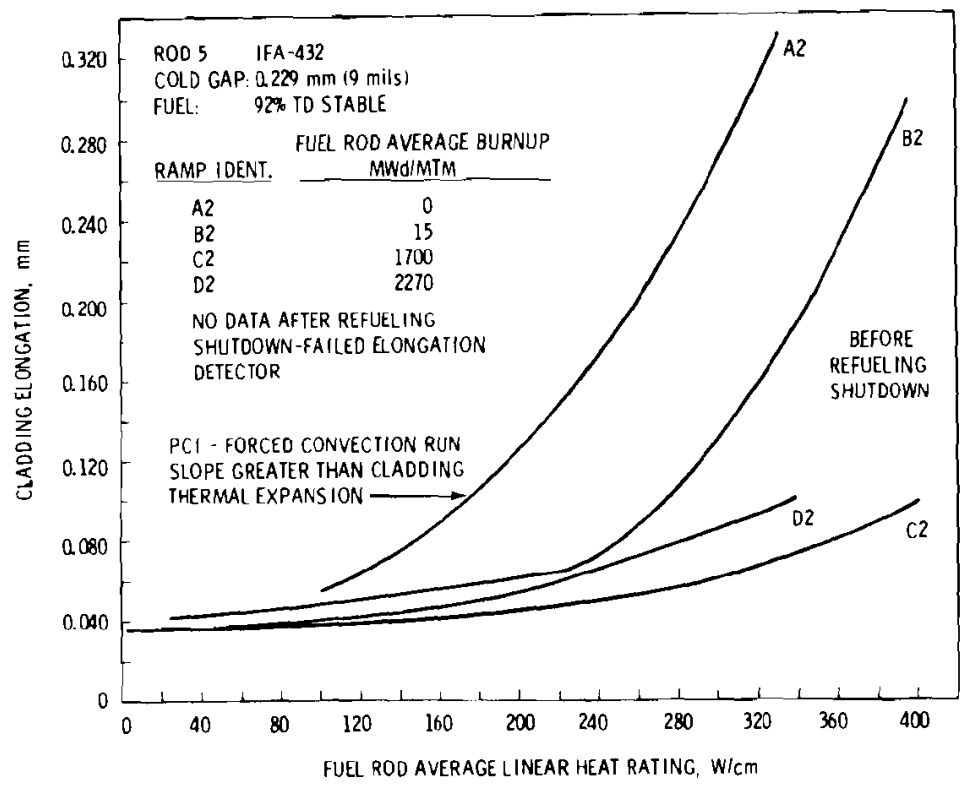

FIGURE 18. Fuel Rod Elongations for Rod 5, IFA-432

(note: The curves have been relocated on the ordinate for comparison purposes and show only relative changes for a specific curve.) 


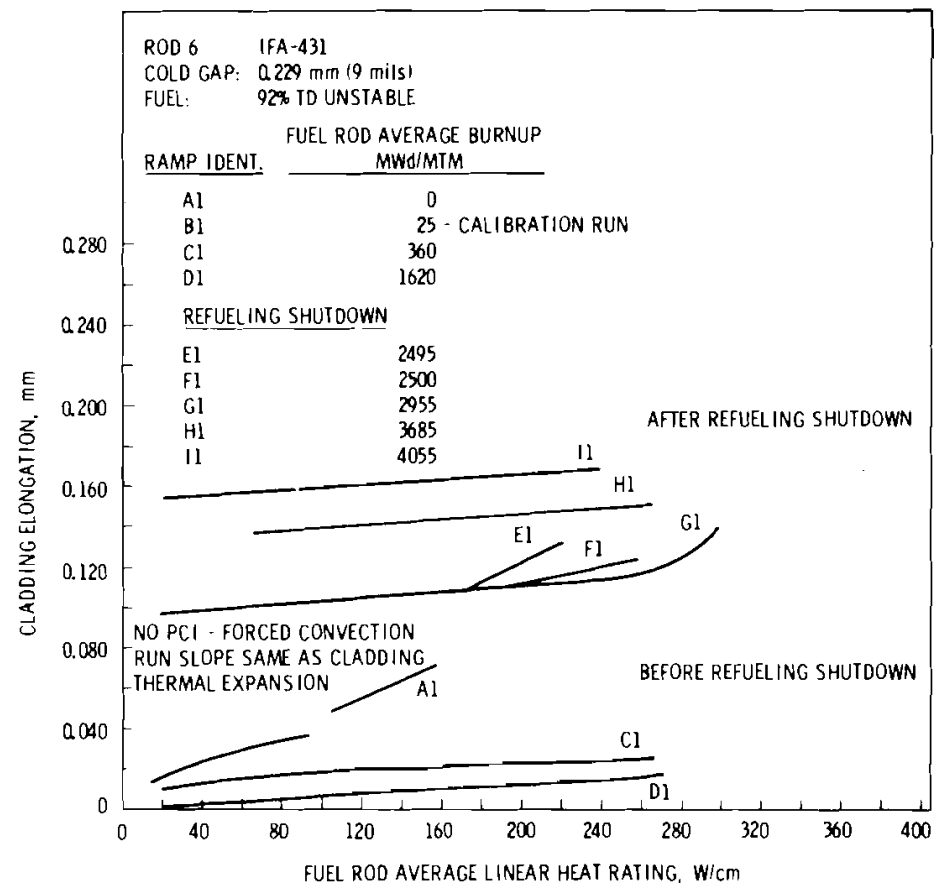

FIGURE 19. Fuel Rod Elongations for Rod 6, IFA-431

(note: The curves have been relocated on the ordinate for comparison purposes and show only relative changes for a specific curve.)

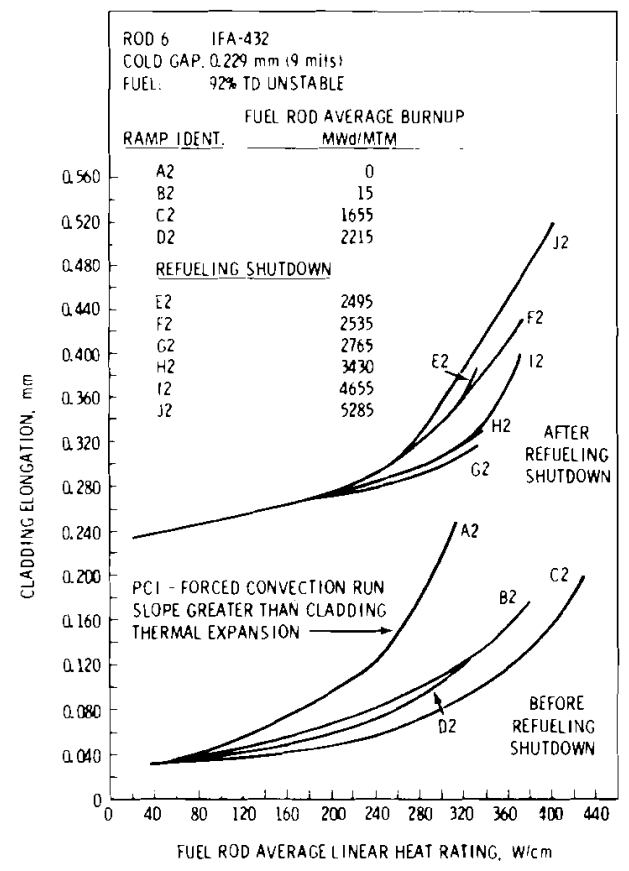

FIGURE 20. Fuel Rod Elongations for Rod 6, IFA-432

(note: The curves have been relocated on the ordinate for comparison purposes and show only relative changes for a specific curve.) 
and D1). PCI occurred in Rod 1 at approximately $270 \mathrm{~W} / \mathrm{cm}(8.2 \mathrm{~kW} / \mathrm{ft}$ ) (Ramp C1). As was noted above, PCI occurred in all of those rods at approximately $170 \mathrm{~W} / \mathrm{cm}$ $(5.2 \mathrm{~kW} / \mathrm{ft}$ ) during the first power ramp (Ramp El) following the refueling shutdown. The occurrence of PCI at lower ALHRs after the shutdown could be attributed to a restacking of the pellet column during the refueling shutdown. It is speculated that complete restacking of all columns could have occurred because of the uniform ALHR at which PCI occurred in the three rods after the refueling shutdown. If the distribution of axial gaps between pellets were different, one would expect PCI to be initiated at different ALHRs in the rods.

Similar comparisons cannot be made for IFA-432 because the elongation detectors for Rods 1 and 5 failed to respond to power increases after the refueling shutdown. In addition, Rod 6 in IFA-432 behaved differently than the other rods. After the refueling shutdown, the ALHR at which PCI occurred increased and then decreased. This trend can be determined from Figure 20 by comparing Ramps E2 and F2 with Ramps G2, H2, and I2 and with Ramp J2. The change in PCI initiation with rod power suggests a stochastic process for the formation and closure of axial gaps between pellets.

A comparison of fuel rod elongations for the fuel rods in IFA-431 after the refueling shutdown for Ramp G1 which occurred at a burnup of approximately $260 \mathrm{GJ} / \mathrm{kgM}$ ( $3000 \mathrm{MWd} / \mathrm{MTM}$ ) is shown in Table 3. This table lists the cladding elongations observed for each rod as a result of an incremental ALHR increase of $50 \mathrm{~W} / \mathrm{cm}(1.5 \mathrm{~kW} / \mathrm{ft})$ from the occurrence of PCI. The results show a possible correlation of cladding elongation with fuel stability (Rod 6). The

\section{TABLE 3. Comparison of Cladding Elongation} for Ramp GI-IFA-431

\begin{tabular}{|c|c|c|c|c|c|c|}
\hline \multirow[b]{2}{*}{ Rod No. } & \multicolumn{2}{|c|}{$\begin{array}{c}\text { ALHR at } \\
\text { occurrence } \\
\text { of PCI }\end{array}$} & \multicolumn{2}{|c|}{$\begin{array}{l}\text { Cladding } \\
\text { Elongation }\end{array}$} & \multirow{2}{*}{\multicolumn{2}{|c|}{$\begin{array}{l}\text { ALHR Incre- } \\
\text { ment for } \\
\text { Measurement }\end{array}$}} \\
\hline & $\overline{\mathrm{W} / \mathrm{cm}}$ & $\mathrm{kW} / \mathrm{ft}$ & $\mathrm{mm}$ & mils & & \\
\hline 1 & 290 & 8.8 & 0.047 & 1.85 & 50 & 1.5 \\
\hline 2 & 260 & 7.9 & 0.015 & 0.59 & 50 & 1.5 \\
\hline 3 & 260 & 7.9 & 0.090 & 3.54 & 50 & 1.5 \\
\hline 5 & 250 & 7.6 & 0.056 & 2.20 & 50 & 1.5 \\
\hline 6 & 250 & 7.6 & 0.030 & 1.18 & 50 & 1.5 \\
\hline
\end{tabular}


elongation for Rod 6 is approximately $35 \%$ less than that for Rod 1 which contained $95 \%$ To stable fuel. This difference could be attributed to fuel densification in the unstable fuel which resulted in less gap closure than that in the rod containing $95 \%$ TD stable fuel.

Rod 2 was designed with a large gap, $0.381 \mathrm{~mm}$ (15 mils), to simulate instantaneous densification. Comparing Rod 6 with Rod 2 shows that the densification in Rod 6 fell far short of the simulated densification in Rod 2.

A similar comparison cannot be made for IFA-432 because the elongation detectors for Rods 1 and 5 were inoperable after the refueling shutdown. However, it is interesting to compare the behavior of Rods 2 and 6 in.IFA-432 after the refueling shutdown (Figures 13 and 20). In Rod 6, axial gaps between pellets appeared to form and then to close, whereas in Rod 2 PCI seemed to occur without the formation of axial gaps as was discussed earlier. This change in mode of PCI could be a function of pellet-cladding gap size. Axial gaps in the pellet stack may form but not close in the sma11 and intermediate gap rods, whereas axial gaps may form and close in rods which have a slightly larger gap, e.g., Rod 6 with fuel subject to densification. The large gap rods (Rod 2) may provide sufficient clearance to preclude the formation of axial gaps in the pellet column.

\section{PRE- AND POSTIRRADIATION MEASUREMENTS}

IFA-431 pre- and postirradiation measurements were made at the Kjeller Hot Laboratory in Norway. The preirradiation measurements were made during May 1975, the postirradiation measurements during August and September 1976. Results for IFA-431 only are given in this report because IFA-432 is still under irradiation at this writing. The results of measured changes in cladding outside diameter and length and deduced residual gap widths are discussed.

Measured Diameter and Length Changes

The results of measured changes in cladding outside diameter and length are shown in Table 4.

Three of the rods show a sma11 permanent diameter strain. The greatest residual diameter change being $0.015 \mathrm{~mm}(0.59 \mathrm{mils})$ for Rod 3 which probably 
TABLE 4. Pre- and Postirradiation Measurements

for Helium Filled Rods - IFA-431

\begin{tabular}{|c|c|c|c|c|}
\hline Rod ivo. & $\begin{array}{c}\text { Diameter } \\
\text { Change } \\
\text { mini(mils }) \\
\end{array}$ & $\begin{array}{c}\text { Preirradiation } \\
\text { Cladding Outside } \\
\text { Diameter } \\
\text { mm (in.) } \\
\end{array}$ & $\begin{array}{c}\text { Length } \\
\text { Change } \\
\operatorname{mim}(\mathrm{mi} 1 \mathrm{~s}) \\
\end{array}$ & $\begin{array}{c}\text { Preirradiation } \\
\text { Cladding Length } \\
\mathrm{mm} \text { (in.) }\end{array}$ \\
\hline 1 & 0 & $12.779(0.5031$ & $0.24(9.4)$ & $645.63(25.420)$ \\
\hline 2 & 0 & $12.779(0.5031)$ & $0.17(6.7)$ & $645.36(25.409)$ \\
\hline 3 & $0.015(0.59)$ & $12.781(0.5032)$ & $0.25(9.8)$ & $645.58(25.417)$ \\
\hline 5 & $0.001(0.04)$ & $12.781(0.5032)$ & $0.18(7.1)$ & $645.62(25.418)$ \\
\hline 6 & $0.005(0.20)$ & $12.776(0.5030)$ & $0.16(6.3)$ & $645.60(25.417)$ \\
\hline
\end{tabular}

was the result of the strong PCI occurring in this rod. Some ridges, with heights up to $12 \mu(0.00047$ in. $)$, were observed from profilometry measurements for Rod 3. No ridging was observed in the other rods.

The residual length elongations are more uniform than the diameter changes with no apparent correlation between the in-reactor rod elongations and residual elongations. Rod 1, in which weak PCI was observed, had essentially the same residual elongation as that of Rod 3 which showed strong PCI. The residual elongations are probably the result of radiation growth and/or stress relaxation.

Deduced Residual Gaps

The Kjeller Research Centre has devised a means to obtain an indication of postirradiation gap width. A lever applies a line force to a fuel rod mounted on a flat support. An interaction curve is produced from which an indication of residual gap width can be deduced. The gap width cannot be adequately deduced from the first displacement curve because of the rounded shape of the curve so this interaction is considered as a conditioning of the fuel rod. The indicators of gap width are taken from subsequent displacement curves. The results of these procedures are presented in Table 5.

These results cannot be correlated with fuel rod PCI behavior. Rods 3 and 5 showed strong PCI and the results show 1 ittle change from the preirradiation nominal gap widths. The results show that Rods 1 and 2, in which weak PCI was observed, have smaller gaps after irradiation while Rod 6 has a larger gap. The latter could be due to densification in the unstable fuel in $\operatorname{Rod} 6$. 
TABLE 5. Results of Deduced Gap Widths

for Helium Filled Rods - IFA-431

\begin{tabular}{|c|c|c|c|}
\hline Rod No. & $\begin{array}{c}\text { Postirradiation } \\
\text { Average Deduced } \\
\text { Gap Width(a) } \\
\text { mm (mils) }\end{array}$ & $\begin{array}{c}\text { Preirradiation } \\
\text { Nominal Gap } \\
\text { Width } \\
\mathrm{mm}(\mathrm{mi} \mathrm{s}) \\
\end{array}$ & Fuel Type ${ }^{(b)}$ \\
\hline 1 & $0.177 \quad(7)$ & $0.229 \quad(9)$ & $95 \%$ TD-S \\
\hline 2 & 0.275 (11) & $0.381 \quad(15)$ & $95 \%$ TD-S \\
\hline 3 & $0.021 \quad(1)$ & $0.051 \quad(2)$ & $95 \%$ TD-S \\
\hline 5 & $0.225 \quad(9)$ & $0.229 \quad(9)$ & $92 \%$ TD-S \\
\hline 6 & $0.282(11)$ & $0.229 \quad(9)$ & $92 \%$ TD-U \\
\hline
\end{tabular}

(a) Average of results from four axial positions on each fuel rod taken at the location of solid pellets.

(b) $T D=$ theoretical density, $S=$ stable fuel, $U=$ unstable fuel. 


\section{REFERENCES}

1. C. E. Beyer, C. R. Hann, D. D. Lanning, R. E. Panisko, and L. J. Parchen, GAPCON-THERMAL-2: A Computer Program for Calculating the Thermal Behavior of an 0xide Fuel Rod. BNWL-1898, Battelle, Pacific Northwest Laboratories, Richland, WA 99352, November 1975.

2. J. A. Dearien, G. A. Berna, M. P. Bohn, D. R. Colemen, P. E. MacDonald and J. M. Broughton, FRAP-S: A Computer Code for the Steady-State Analysis of Oxide Fuel Rods. SRD-52-76, Aerojet Nuclear Company, INEL, Idaho Fal1s, ID 83401, January 1976.

3. R. E. Williford and C. R. Hann, "Effects of Fill-Gas Composition and Eccentric Gap Geometery on Gap Conductance of $\mathrm{UO}_{2}$ Fuel Rods," Trans. Am. Nucl. Soc., Vol. 26, p. 324, 1977.

4. C. R. Hann et al., Test Design, Pre-Characterization and Fuel Assembly Fabrication for Instrumented Fuel Assemblies IFA-431 and IFA-432, BNWL-1988, Ju1y 1976. 



\section{DISTRIBUTION}

Ho. of

Copies

OFFSITE

1

ERDA Chicago Patent Group

9800 S. Cass Avenue

Argonne, Illinois 60439

A. A. Churm

245 ERDA Technical Information Center For Basic Distribution Under NRC-1

61 Supplementary IIRC-3 Distribution List

3 ERDA Technical Information

1.. Jinks

Chief Mail \& Files

US NRC Central Files

Washington, D.C. 20555

10 Huclear Regulatory Commission, Division of Reactor Safety Research

W.V. Johinston, Chief, Fuel Behavior Research Branch, Wash. D.C. 20545

ONSITE

1

ERDA Richland Operations

Office

Program Division

H. E. Ransom

63

Battelle-iNorthwest

C.R. Hann (4)

R.K. Marshall (30)

Technical Information Files (5)

Technical Publications
W.J. Bailey
J.0. Barner
S. Begej
E.R. Bradley
D.W. Brite
T.D. Chikalla
J.A. Christensen
E.L. Courtright
M.E. Cunningham
M.D. Freshley
D.D. Lanning
R.P. Marsha11
J.F. Garnier
L.L. King
C.L. Mohr
R.D. Nelson
A.R. 01 sen
F.E. Panisko
P.J. Pankaskie
A.M. Sutey
D.S. Trent
S.R. Wagoner
R.E. Williford
C.L. Wilson 
